\title{
GVF27, a human derived peptide with anti-infective properties against biofilm forming members of the Burkholderia cepacia complex
}

\section{Andrea Bosso}

University of Naples Federico II: Universita degli Studi di Napoli Federico II

\section{Rosa Gaglione}

University of Naples Federico II: Universita degli Studi di Napoli Federico II

\section{Rocco Di Girolamo}

University of Naples Federico II: Universita degli Studi di Napoli Federico II

\section{Edwin Veldhuizen}

Utrecht University: Universiteit Utrecht

\section{Pilar García-Vello}

University of Naples Federico II: Universita degli Studi di Napoli Federico II

\section{Salvatore Fusco}

University of Verona: Universita degli Studi di Verona

\section{Valeria Cafaro}

University of Naples Federico II: Universita degli Studi di Napoli Federico II

\section{Rosanna Culurciello}

University of Naples Federico II: Universita degli Studi di Napoli Federico II

\section{Eugenio Notomista}

University of Naples Federico II: Universita degli Studi di Napoli Federico II

\section{Angela Arciello}

University of Naples Federico II: Universita degli Studi di Napoli Federico II

Elio Pizzo ( $\nabla$ elipizzo@unina.it )

University of Naples Federico II: Universita degli Studi di Napoli Federico II https://orcid.org/0000-00023652-8865

\section{Research}

Keywords: burkholderia, cenocepacia, biofilm, human, gvf27

Posted Date: September 23rd, 2021

DOI: https://doi.org/10.21203/rs.3.rs-923973/v1 
License: (c) (i) This work is licensed under a Creative Commons Attribution 4.0 International License. Read Full License 


\section{Abstract}

Therapeutic solutions to counter Burkholderia cepacia complex (Bcc) bacteria are challenging due to their intrinsically high level of antibiotic resistance. Bcc organisms display a variety of potential virulence factors, have a distinct lipopolysaccharide naturally implicated in antimicrobial resistance and are able to form biofilms, which may further protect them from both host defence peptides (HDPs) and antibiotics. Here, we report the extremely promising anti-biofilm and immunomodulatory activities of human HDP GVF27 on two of the most clinically relevant Bcc members, as Burkholderia multivorans and Burkholderia cenocepacia. The effects of synthetic and labelled GVF27 were tested on B. cenocepacia and $B$. multivorans biofilms, at three different stages of formation, by alternative microscopy approaches. Assays on bacterial cultures and on human monocytes challenged with B. cenocepacia LPS, were also performed. GVF27 exerts, at different stages of formation, meaningful anti-biofilm effects towards both Bcc strains, a significant propensity to function in combination with ciprofloxacin, a relevant affinity for LPSs isolated from Burkholderia cenocepacia as well as a good propensity to mitigate the release of proinflammatory cytokines in human cells pre-treated with the same endotoxin. Overall, all these findings contribute to the elucidation of the main features that a good therapeutic agent directed against these extremely leathery biofilm-forming bacteria should possess.

\section{Introduction}

Multi-drug resistance in bacteria is one of the most pressing global health issues of our time [1, 2]. Current approaches to counteract antimicrobial resistance focus primarily on two main challenges, i.e., ensuring a more prudent and efficient use of existing antibiotics and making available new antimicrobial agents. The latter clearly requires great efforts and significant investments addressed to the identification and development of new effective molecules [3]. An extremely promising source of new anti-infective molecules is represented by host defence peptides (HDPs), short molecules (10-50 residues in length) mostly characterized by a net positive charge and a high proportion of hydrophobic amino acids, naturally occurring and produced by most living beings, spanning from microbes to mammals $[4,5]$. HDPs are a widely distributed family of molecules for the treatment of various bacterial infections, including opportunistic ones, with additional properties concerning the ability to steer innate and adaptive immunity $[4,6]$. HDPs attenuate immune response through several types of actions, as binding to endotoxins, contribution to the enhancement of innate immune processes by promoting chemotaxis of neutrophils, monocytes, eosinophils, dendritic cells and T-lymphocytes to the site of infection, stimulation of chemokine production and modulation of wound healing/re-epithelialization of injured infected tissues [7-11]. This wide range of properties attribute to HDPs a critical role in mammalian innate immunity and makes them very attractive as an effective alternative to conventional antibiotics for developing new antiinfective agents $[12,13]$. However, resistant bacteria intrinsically able to counteract HDPs activity have been reported, including the well characterized group of Burkholderia cepacia complex (Bcc). This group of Gram negative closely-related species phylogenetically but not phenotypically distinguishable, known also as genomovars, cover a prominent role in determining serious health risks with drastically limited 
treatment options in immunocompromised individuals $[14,15]$. Bcc bacteria, particularly $B$. cenocepacia and $B$. multivorans strains, generally display an intrinsic resistance to clinically relevant antibiotics [14, 16] mediated by mechanisms as enzymatic inactivation ( $\beta$-lactamases, aminoglycoside-inactivating enzymes, dihydrofolate reductase), alteration of drug targets, cell wall impermeability and activation of efflux pumps $[17,18]$. Their pathogenicity is also promoted by several virulence determinants $[16,19,20]$ that, together with an extraordinary metabolic versatility [21], allows their adaptation to a wide range of environments, thus making the treatment of Burkholderia infections particularly tough.

Extracellular lipases, metalloproteases and serine proteases are involved in the interaction with host cells [22]. While metalloproteases and serine proteases seem to play a role in the proteolysis of the extracellular matrix and are produced by many but not all the Bcc species [23], lipases are thought to be involved in the invasion and their production is broadly distributed among the members of the Bcc [24]. Moreover, bacterial surface structures, such as lipopolysaccharides (LPSs), flagella and pili, are pivotal in the interaction with the host as they are able to subvert innate immune receptors (e.g. toll-like receptors TLRs), thus inducing a disproportionate pro-inflammatory cytokine response [25]. In particular, LPSs purified from Bcc were found to exhibit in vitro a higher endotoxic activity and to induce a more pronounced cytokine response in human leukocytes and macrophages compared to LPS from several cystic fibrosis clinical isolates of Pseudomonas aeruginosa [26, 27]. Structural analyses on different LPSs purified from Bcc suggest also that their unusually high pro-inflammatory activity is mostly linked to differences in the acylation state of lipid $A[26,28,29]$. In addition, the modification of phosphate groups in lipid A with 4-amino-4-deoxy-I-arabinose (I-Ara4N), is a strategy that allows a proper assembly of LPSs at the outer membrane and probably is the most critical determinant for the intrinsic resistance of most of these bacteria to antimicrobial peptides [30]. The picture that emerges from all these considerations clearly indicates that Bcc members evade host innate immune system through multiple mechanisms and, for this reason, the discovery of molecules capable of effectively fighting these pathogens acquires an indisputable priority in the context of multi-drug resistance.

Numerous human proteins, not necessarily directly involved in host defence, are potential reservoir of HDPs hidden inside their sequences [31-33]. Among these, the 11-hydroxysteroid dehydrogenase-1 $\beta$-like (accession number UniProtKB: Q7Z5J1) has proven to be a promising precursor protein. This latter is an enzyme in which a potent antimicrobial peptide, GVF27, was identified and described for its structural and anti-infective properties [34]. This paper focuses on a panel of bioactivities of GVF27 specifically directed against two extremely virulent members of Bcc, such as B. cenocepacia and B. multivorans. In particular, we report that GVF27 exerts: i) meaningful anti-biofilm effects towards these two Bcc strains, ii) the ability to function in combination with the ciprofloxacin antibiotic, iii) a strong affinity for LPS as well as iv) a good propensity to mitigate the release of pro-inflammatory cytokines in human cells treated with the same endotoxin. Overall, these findings contribute to the elucidation of the main features that a good therapeutic agent directed against these extremely leathery biofilm-forming bacteria should possess. 


\section{Results}

\section{Anti-biofilm activity of GVF27 on Bcc clinical isolates}

As previously reported [34], GVF27 proved to exert a powerful antimicrobial activity on biofilm-forming $E$. coli, showing a significant propensity to reduce the microbial load and disrupt the biofilm mass. Here, we evaluated the anti-biofilm properties of GVF27 on Bcc bacteria and, to do this, we selected two clinical isolates: B. cenocepacia LMG 18863 and B. multivorans LMG 17582. To assess the effects of GVF27 on the three main stages of biofilm development (attachment, formation and detachment), increasing concentrations of the peptide (from 0.078 to $20 \mu \mathrm{M}$ ) were tested. In each case, following incubation with the peptide, biofilm was analysed by staining with crystal violet, a dye which stains both cells and extracellular material, thus allowing to determine the total biofilm mass. As shown in Fig. 1, GVF27 was found to be effective at peptide concentrations lower than those required to directly kill planktonic cells (Table 2) or to induce a significant decrease of their growth rate (Fig. 2). Biofilm attachment and formation were affected in a similar percentage in the case of both bacterial strains, whereas apparently GVF27 did not exert significant effects on preformed biofilm even at the highest doses tested. To further investigate anti-biofilm properties of GVF27 on both strains, analyses were also performed by confocal laser scanning microscopy (CLSM). In this case, the three main stages of biofilm development were analyzed and peptide effects were evaluated through the use of two staining procedures allowing to quantify live cells, dead cells and extracellular material: LIVE/DEAD BacLight kit and FilmTracer SYPRO Ruby biofilm matrix stain. The first staining kit exploits two dyes, the green-fluorescent SYTO 9 9 dye and the red-fluorescent propidium iodide, to discriminate between living cells (green) and dead or dying ones with a compromised membrane (red). On the other hand, FilmTracer SYPRO Ruby, specifically stains biofilm extracellular matrix. Images in Figs. 3-5 clearly indicate that GVF27 is able to affect bacterial viability in a dose dependent manner by affecting all the three biofilm stages tested. Moreover, images collected in panels $\mathbf{A}$ and $\mathbf{C}$ of each figure also suggest that the peptide is able to induce a significant alteration of biofilm matrix architecture. This indication is also observable in fluorescence analyses shown in Fig. 6 (Panels A-F), where it appears clearly evident that treatment with the peptide determines a significant decrease of samples fluorescent staining, with effects even more accentuated in the case of $B$. cenocepacia LMG 18863. It is worth mentioning that, even if this observation appears in contrast with evidence collected upon samples staining with crystal violet (Fig. 1, grey bars), it is particularly relevant considering that the peptide was tested on three different phases of biofilm development and that, unlike crystal violet staining, analyses by confocal microscopy allow to deeply analyse biofilm morphology, biovolume and size. This suggests that GFV27 can counteract both the early stages of biofilm matrix organization, during the transition from planktonic to the sessile form, and the advanced ones in which the transition to the sessile form is complete and a peculiar molecular framework has been already formed to protect the cells encapsulated inside. Further analyses were carried out to determine possible effects of GVF27 on total biomass (thickness) of biofilm of both strains. In this regard, once threedimensional images were collected and optical Z-sections at $1 \mu \mathrm{m}$ intervals were obtained from the bottom to the top of the biofilm, we determined average thickness measurements by Zen Black software 
(see Methods) and noted that GVF27 presented a good propensity to mitigate biofilm biomass enhancement of both bacterial strains (Fig. 6, panels $\mathbf{g}$ and $\mathrm{h}$ ). As previously shown in Fig. 5, GVF27 was able to eradicate preformed biofilm of B. cenocepacia $L M G 18863$ (panel A and B) and B. multivorans LMG 17582 (panel $C$ and D) when administered at $5 \mu \mathrm{M}$ and $2.5 \mu \mathrm{M}$, respectively. However, we can reasonably assume that the peptide was active also at the highest concentrations tested, since the denser thickness detected (purple lines in Fig. 6, panels $\mathbf{g}$ and $\mathbf{h}$ ) could be the result of a greater number of eradicated and fluctuating planktonic cells in the scan region $(6-12 \mu \mathrm{m})$, whereas the maximum coverage surface of the matrix was generally concentrated in the regions between 0 to $6 \mu \mathrm{m}$. To support these findings, a time course analysis of the interaction between GVF27 and biofilm components of $B$. cenocepacia LMG 18863 was also performed. To this purpose, the interaction of GVF27, labelled to its Nterminus with 5,6-carboxyfluoresceine (FAM-GVF27), with B. cenocepacia biofilm has been evaluated over a time interval of 240 minutes. Time-lapse video of biofilm formation (video clip S1) as well as Fig. 7 clearly confirms that GVF27 is able to progressively interact with biofilm components and planktonic cells.

\section{Studies Of Agglutinating Activity}

In order to protect the bacteria against desiccation and host immune defences, a variety of exopolysaccharides are required for the development and integrity of bacterial biofilm architecture. The production of poly- $\beta 1,6-\mathrm{N}$-acetylglucosamine (PNAG), also known as "polysaccharide intercellular adhesin" (PIA), an important virulence factor well characterized in different bacterial biofilms, has been documented in several Bcc biofilms [35] in which it contributes to resistance to multiple antibiotics and persistence during chronic infections. Based on previously reported ability of GVF27 to induce LPS aggregation [34], a feature suggesting a putative ability of the peptide to promote bacterial agglutination, a further test was performed on B. cenocepacia LMG 18863 static biofilms by CLSM upon treatment with GVF27 and staining of PNAG (see methods). As shown in Fig. 8, GVF27 was able to promote agglutination of bacteria during biofilm formation at significantly lower concentration values than $\mathrm{MIC}_{100}$ values determined on planktonic cells (Table 2). In particular, the minimal agglutination concentration (MAC) value, defined as the minimal peptide concentration able to induce agglutination of bacteria, was estimated to be about 60 times lower than $\mathrm{MIC}_{100}$ determined on planktonic cells $(0.625 \mu \mathrm{M} v s 40 \mu \mathrm{M})$. This result suggests a very high affinity of GVF27 for specific biofilm components and swimming bacteria. Moreover, as reported in the same figure (panel e-h), the agglutination induced by GVF27 occurs in a dose dependent manner with a steady state reached between $5 \mu \mathrm{M}$ and $40 \mu \mathrm{M}$ (panels A-D). To further investigate the agglutinating ability of GVF27, a time-lapse video of the biofilm formation was recorded by using FAM-GVF27 and SYPRO Ruby to stain extracellular matrix. As visible in the video clip S2 as well as in the Fig. 9, this peptide is able to progressively interact with biofilm components in a time dependent manner, as highlighted by an overlap between the blue signal (peptide) and the extracellular matrix (red signal) resulting in an accumulation of magenta signal. Possible morphological modifications of B. cenocepacia LMG 18863 biofilm upon treatment with GVF27 were also analysed by scanning 
electron microscopy (SEM). As shown in Fig. 10 (top left panels), untreated bacteria presented smooth and intact surfaces and appeared embedded into an extracellular biofim matrix (black arrows). When bacterial biofilm was treated with increasing doses of peptide, instead, a significant decrease or disappearance of biofilm matrix was clearly measurable with a concomitant decrease of cell density. Interestingly, this trend was dependent from peptide dose until $5 \mu \mathrm{M}$, after which a kind of plateau was reached likely due to excess of peptide.As Bcc biofilms are commonly recalcitrant to antibiotics, it was also verified whether GVF27 had the ability to synergistically act in combination with antimicrobial agents which were ineffective as such on these strains. To this purpose, CLSM analyses were performed to evaluate the effects of combinations of GVF27 and ciprofloxacin on preformed biofilms of $B$.

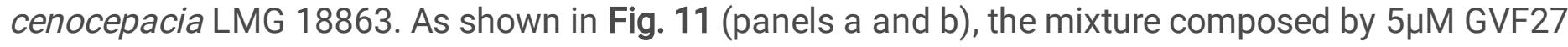
and $5 \mu \mathrm{M}$ ciprofloxacin induced a more effective reduction of biofilm (with an additive effect) together with the concomitant increase of the number of dead cells embedded into the biofilm matrix with respect to the treatment with single agents. This result was further corroborated by the evidence that the mixture GVF27/ciprofloxacin $(1: 1, \mathrm{~mol} / \mathrm{mol})$ had a significant increased ability to reduce the thickness of the preformed biofilm (see Fig. 11, panel c).

\section{Interaction studies of GVF27 with LPS and immunomodulation assays on THP-1 cells}

LPSs from Bcc are potent immune stimulators that activate human Toll-like Receptor 4 (TLR4) and significantly contribute to host cell damage [36]. Many of the relevant aspects of Bcc behaviour can be ascribed to the peculiar physicochemical properties of the external layer of their cell wall, the architecture of which is in turn determined by the molecular structure of the constituting LPSs. As previously described, the main structural peculiarities of Bcc LPSs are represented by the presence of Ara4N residues on the lipid $A$ backbone and by the Ko substitution in the oligosaccharide core, which together contribute significantly to the neutralization of anionic charges present on the bacterial cell surface, thus increasing the difficulty of cationic antibiotics (e.g., polymyxin, colistin) to bind to the cell surface. Previous data indicate that GVF27 is able to assume specific conformations in the presence of LPSs isolated from different strains, including also some clinical isolates of Pseudomonas aeruginosa, and to promote the formation of larger LPS micelles [34]. These pieces of evidence inspired us to verify whether GVF27 could possess the ability to neutralize LPS associated to Bcc. A first test was carried out using the carboxy-fluorescein labelled version of GVF27 (FAM-GVF27) to analyse its behaviour in the presence of LPSs from B. cenocepacia ET-12 J2315, a highly epidemic and virulent strain. Since emission intensity of fluorescein, like that of other high extinction coefficient fluorophores, is very sensitive to self-quenching, it can be expected that binding of fluorescein-labelled peptide to LPS should provoke a decrease in fluorescence intensity. A plot obtained by measuring the fluorescence intensity (at $520 \mathrm{~nm}$ ) of $1.25 \mu \mathrm{M}$ FAM-GVF27 emitted in the presence of increasing concentrations of LPS ET-12 J2315 (from 2.4 to 150 $\mu \mathrm{g} / \mathrm{ml}$ ) is shown in Fig. 12. Under the same conditions, the peptide was analysed also in the presence of three different LPSs, two isolated from Pseudomonas aeruginosa strains and one from Escherichia coli. Collected results clearly indicate that FAM-GVF27 interacts with LPSs at sub-micellar concentrations. 
This direct interaction between GVF27 and LPS could be part of a LPS neutralization mechanism that the peptide exploits to inhibit or strongly counteract the interaction of the endotoxin with LPS-binding protein (LBP) and the subsequent activation of TLR4. To analyse further the possible direct interaction between GVF27 and LPS ET-12 J2315, an isothermal titration calorimetry (ITC) analysis was used and a strong interaction was observed (Fig. 13 panel a). In detail, GVF27 bound to LPS exothermically $(\Delta \mathrm{H}=-28.6$ $\mathrm{kJ} / \mathrm{mol})$ with a dissociation constant $\mathrm{Kd}=61 \mathrm{nM}$. Interestingly, a positive entropy was measured $(\Delta \mathrm{S}=$ $48.5 \mathrm{~J} / \mathrm{mol} . \mathrm{K}$ ) contributing to binding and indicative of hydrophobic interactions between the peptide and LPS. A strong association was also observed between GVF27 and E. coli LPS but with different binding characteristics. The actual dissociation constant was in the same range as for LPS ET-12 J2315 (93 nM) but the enthalpy was twice as high $(\Delta \mathrm{H}=-57.35 \mathrm{~kJ} / \mathrm{mol})$, while the entropy was negative $(\Delta \mathrm{S}=-57.4$ $\mathrm{J} / \mathrm{mol} . \mathrm{K}$.). This indicates that this interaction is fully enthalpy-driven and, therefore, more dependent on electrostatic interactions between LPS and GVF27. Finally, binding ratios were higher for GVF27 and LPS ET-12 J2315 (almost 2.9 molecules GVF/LPS vs 1.7), but this is based on estimated molecular weights of both LPSs of $15 \mathrm{kDa}$, so more detailed studies would be required to determine whether the binding ratio is indeed significantly different. In support of this evidence, further investigations were then carried out to verify whether GVF27 could be also able to reduce TLR4 dependent activation of inflammatory mediators on human THP-1 cells infected with the same endotoxin. Preliminarily to this, biocompatibility of GVF27 on undifferentiated and PMA-differentiated THP-1 cells was verified by testing the effects of the peptide (at 5 and $20 \mu \mathrm{M}$ ) and slightly toxic effects were detected only on undifferentiated THP-1 cells at the highest concentration tested (Fig. 13 panels b and c). Interestingly, when GVF27 was tested at the same doses but in the presence of $1 \mu \mathrm{g} / \mathrm{ml}$ LPS ET-12 J2315, undifferentiated THP-1 cell viability was restored to values that were identical to those obtained in the case of untreated cells, thus highlighting once again the ability of the peptide to bind to the endotoxin, thus becoming unavailable to the interaction with cells (Fig. 13 panel c). ELISA experiments were then performed to investigate whether GVF27 was able to alter TNF- $\alpha$ and MCP-1 release in LPS treated undifferentiated and PMA-differentiated THP-1 cells. The results shown in Fig. 13 (panels d-e) clearly support the hypothesis that GVF27 is able to interfere with the infection. Indeed, as shown in Fig. 13, both in the case of LPS induced undifferentiated and PMAdifferentiated THP-1 cells, GVF27 mitigates in a dose dependent manner the release of TNF- $a$ and the same promising trend was obtained also for MCP-1 in LPS-induced PMA-differentiated THP-1 cells (Fig. 15 panel F).

\section{Discussion}

Epidemiological surveys revealed that the most clinically relevant Bcc species, especially in immunocompromised patients, are Burkholderia multivorans and Burkholderia cenocepacia [37]. Treatment of infections caused by these species is often poorly effective due to their inherently resistance to antimicrobial agents [38]. One of the main resistance determinants in these species is represented by the constitutive presence of Ara4N linked to the lipid A phosphate groups in the LPS that eliminates the negative charge required for polymyxin binding and presumably blocks the self-promoted uptake generally utilized by polycationic antimicrobials. Besides this peculiar composition of LPS, the 
contribution of other genes, such as ispH (involved in the synthesis of isoprenoids), norM (an efflux pump-encoding gene), and hpnJ (encoding hopanoid) as well as enzymatic inactivation and alteration of drug targets, play roles in the multifaceted mechanisms that result in high levels of resistance to polycationic antimicrobials in these Bcc members [20,38]. In addition, biofilm-associated cells increase tolerance to antimicrobials by reduction of drug penetration, a lower growth rate of sessile cells, the expression of specific resistance genes and the presence of persister cells typically considered as "dormants"[39]. Even when therapies are based on high doses of antibiotics known to be effective against Bcc species in vitro, it is often impossible to clear the infection. Nevertheless, as there are exceptions to every rule and this could also apply to these organisms, here we report the meaningful antibiofilm and immunomodulating properties against $B$. multivorans and $B$. cenocepacia of GVF27, a human cryptic host defence peptide derived from the 11-hydroxysteroid dehydrogenase-1 $\beta$-like [34]. Multiple approaches here described clearly indicate that GFV27 can counteract both the early stages of biofilm matrix organization, during the transition from planktonic to the sessile form, and the advanced ones in which the transition to the sessile form is complete and a peculiar molecular framework has been already formed to protect the cells encapsulated inside. Moreover, CLSM and time-dependent localization analysis clearly indicate that GVF27 is able to progressively interact with different biofilm components and cells, while inducing a significant reduction and alteration of biomass. It is widely reported that antibiotics for therapeutic use (aminoglycosides, fluoroquinolones, tetracycline and other) work poorly in chronic infections, acting in some cases as inter-microbial signaling agents that stimulate bacterial biofilm formation instead as weapons [40, 41]. Interestingly, in our experiments, we found that anti-biofilm properties of GVF27 are even more pronounced when the peptide is administered in combination with ciprofloxacin. Indeed, CLSM analyses performed to evaluate the effects of combinations of GVF27 and ciprofloxacin on preformed biofilms of Burkholderia cenocepacia LMG 18863 allowed us to detect a more effective reduction of biofilm together with a concomitant increase of the number of dead cells embedded into the biofilm matrix with respect to the treatment with single agents, thus indicating a significant additive effect. These data further support the idea that GVF27 could ideally act as a treadmill for those agents unable to overcome the narrow and impervious scaffolding of the biofilm. Most Bcc isolates recovered from immunocompromised patients produce large amounts of exopolysaccharides (EPS), such as poly- $\beta-1,6-N$-acetylglucosamine (PNAG), suggesting a possible role of this EPS in Bcc pathogenesis [42]. To investigate the putative agglutinating activity of GVF27, tests on Burkholderia cenocepacia static biofilms upon treatment with the peptide and staining of PNAG were also performed. Minimal agglutination concentration (MAC) values detected suggest a very high affinity of GVF27 for PNAG and also for swimming bacteria. In addition, SEM analyses highlighted that the extracellular matrix produced by Burkholderia cenocepacia significantly reduces in the presence of GVF27. All these findings, in agreement with other studies in which it was highlighted that PNAG is needed to form and maintain the integrity of Burkholderia biofilms [43], support the idea that the peptide may exert its antibiofilm activity by mechanisms that go beyond a direct microbicidal effect, thus suggesting, as above mentioned, that their use, alone or in combination with other conventional or unconventional drugs, may represent an effective strategy to target biofilm cells. In addition, interaction studies of GVF27 with LPS isolated from Burkholderia cenocepacia ET-12 J2315 strain, a highly epidemic and virulent strain, indicate that the 
peptide is able to efficiently bind also to this endotoxin. This propensity was observed not only in vitro by ITC experiments but also in human monocyte cultures in which it was possible to highlight a significant mitigation of inflammatory mediators when cells were subjected to treatment with the endotoxin. These findings significantly integrate the range of potential effects of GVF27 on these two Bcc strains and clearly make it adaptable to function as a suitable template to design effective drugs for the treatment of MDR organisms. To our knowledge, GVF27 is the only unmodified cryptic human peptide, in terms of sequence and amino acid residues, to exhibit such a broad spectrum of bioactivities towards Burkholderia multivorans and Burkholderia cenocepacia. The global increase in multidrug-resistant pathogens along with a steady decline in the discovery of new antibiotics underscores the need for new therapies to control infections; the case of GVF27 confirms how immense and practically still unknown is the potentiality of the human proteome as a guiding tool for the design of new generation peptide therapeutic agents.

\section{Methods}

\section{Materials}

All chemicals were purchased from Merck KGaA (Darmstadt, Germany), unless specified otherwise.

\section{Peptide Synthesis}

GVF27, FAM-GVF27 and LL-37 were synthesized by the solid-phase method (CASLO ApS, Lyngby, Denmark). FAM-GVF27 presents 5,6 - carboxyfluoresceine fluorochrome conjugated to the N-terminus of peptide. The purity of all the three peptides was determined by analytical HPLC to be higher than $95 \%$. Trifluoroacetic acid (TFA) was removed and the molecular weight was confirmed by MALDI-TOF mass spectrometry. Peptide sequences are reported in Table 1.

\section{Bacterial strains and growth conditions}

Clinical isolates Burkholderia cenocepacia LMG 18863 and Burkholderia multivorans LMG 17582 were kindly provided by Dr. Alessandra Bragonzi (Infection and CF Unit, San Raffaele Scientific Institute, Milan, Italy). Both bacterial strains were grown in Muller Hinton Broth (MHB, Becton Dickinson Difco, Franklin Lakes, NJ) and on Tryptic Soy Agar (TSA; Oxoid Ltd., Hampshire, UK). In all the experiments, bacteria were inoculated and grown overnight in $\mathrm{MHB}$ at $37^{\circ} \mathrm{C}$. The next day, bacteria were transferred to a fresh MHB tube and grown to mid-logarithmic phase.

\section{Antimicrobial activity}

The antimicrobial activity of GVF27, FAM-GVF27 and LL-37 on B. cenocepacia LMG 18863 and $B$. multivorans LMG 17582 was determined by using the broth microdilution method, as previously described [44]. Bacteria were grown to mid-logarithmic phase in MHB at $37^{\circ} \mathrm{C}$, then diluted to $2 \times 10^{6}$ $\mathrm{CFU} / \mathrm{mL}$ in Difco 0.5X Nutrient Broth (Becton-Dickenson, Franklin Lakes, $\mathrm{NJ}$ ) and mixed 1:1 v/v with two- 
fold serial dilutions of peptides. Following over-night incubation, $\mathrm{MIC}_{100}$ values were determined as the lowest peptide concentration responsible for no visible bacterial growth. All the experiments were carried out in three independent replicates.

\section{Cell Culture and Differentiation}

Human monocytic cells THP-1 (ATCC, TIB-202) were cultured in Roswell Park Memorial Institute 1640 medium (RPMI) completed with $10 \%$ fetal bovine serum, $100 \mu \mathrm{g} / \mathrm{mL}$ penicillin and $100 \mu \mathrm{g} / \mathrm{mL}$ streptomycin and stored in a humidified $37{ }^{\circ} \mathrm{C}$ incubator with $5 \% \mathrm{CO}_{2} / 95 \%$ air. Cells were periodically checked at the microscope to ensure normal morphology.THP-1 cells were differentiated using $2 \mathrm{nM}$ phorbol 12-myristate 13 -acetate (PMA) for $96 \mathrm{~h}$ at $37{ }^{\circ} \mathrm{C}$ with $5 \% \mathrm{CO}_{2} / 95 \%$ air.

\section{Cytotoxicity assays}

Cytotoxic effects of GVF27 on undifferentiated or PMA-differentiated THP-1 cells were determined by performing the 3-(4,5-dimethylthiazol-2-yl)-2,5 diphenyltetrazolium bromide reduction inhibition assay (MTT assay), designed to be used for the spectrophotometric quantification of cell proliferation. Briefly, $2 \times 10^{4}$ cells were seeded into a 96 -well plate and incubated at $37^{\circ} \mathrm{C}$ in the presence of $5 \% \mathrm{CO}_{2}$. Medium was then replaced with $100 \mu \mathrm{L}$ of fresh medium containing peptide solution at a final concentration ranging from 0 to $40 \mu \mathrm{M} /$ well. After $24 \mathrm{~h}$ of incubation at $37^{\circ} \mathrm{C}$, the peptide-containing medium was removed, and $100 \mu \mathrm{L}$ of tetrazolium MTT diluted at $0.5 \mathrm{mg} / \mathrm{mL}$ in DMEM without red phenol was added. After $4 \mathrm{~h}$ of incubation at $37^{\circ} \mathrm{C}$, the resulting insoluble formazan salts were solubilized in $0.04 \mathrm{M} \mathrm{HCl}$ in anhydrous isopropanol and quantified by measuring the absorbance at $\lambda=570 \mathrm{~nm}$, using an automatic plate reader spectrophotometer (Synergy HTX Multi-Mode Reader-BIOTEK, Winooski, Vermont, United States). Cell survival was expressed as means of the percentage values compared to control. Analyses were performed at last 3 times.

\section{Anti-biofilm activity assays}

Bacteria were grown over-night at $37^{\circ} \mathrm{C}$ and then diluted to $4 \times 10^{8} \mathrm{CFU} / \mathrm{mL}$ in $0.5 \times \mathrm{MHB}$. Incubations with increasing concentrations of GVF27 (from 0.078 to $20 \mu \mathrm{M}$ ) were carried out either for $4 \mathrm{~h}$, in order to test peptide effects on cells attachment, or for $24 \mathrm{~h}$, in order to test peptide effects on biofilm formation, as previously described [45]. When the effects of peptides on preformed biofilm were evaluated, bacterial biofilm was formed for $24 \mathrm{~h}$ at $37^{\circ} \mathrm{C}$, and then treated with GVF27. To carry out the crystal violet assays, bacterial biofilms were washed with PBS $1 \mathrm{X}$ and then incubated with the dye $(0.04 \%)$ for 20 min at room temperature. At the end of the incubation and after a further wash with PBS 1X, the dye bound to cells was dissolved in 33\% acetic acid. Spectrophotometric analyses were then carried out at a wavelength of $600 \mathrm{~nm}$.

Confocal laser scanning microscopy analyses in static conditions were performed by using Thermo Scientific ${ }^{\text {TM }}$ Nunc $^{\text {TM }}$ Lab-Tek $^{\text {TM }}$ Chambered Coverglass systems (Thermo Fisher Scientific, Waltham, MA, USA). Viability of the cells embedded into biofilm structure was evaluated by sample staining with either 
LIVE/DEAD ${ }^{8}$ Bacterial Viability kit (Molecular Probes Thermo Fisher Scientific, Waltham, MA, USA) or with FilmTracer ${ }^{T M}$ SYPRO ${ }^{T M}$ Ruby Biofilm Matrix Stain (Invitrogen ${ }^{T M}$ ) accordingly to manufacturers' instructions. Biofilm images were captured by using a confocal laser scanning microscope (Zeiss LSM 710 , Zeiss, Germany) and a $63 \mathrm{X}$ objective oil-immersion system. Biofilm architecture was analysed by using the Zen Lite 2.3 software package. Each experiment was performed in triplicate. All the images were taken under identical conditions.

\section{Minimal agglutination concentration (MAC)}

B. cenocepacia LMG 18863 cells were grown at $37^{\circ} \mathrm{C}$ to an $\mathrm{OD}_{600 \mathrm{~nm}}$ of 0.2 , centrifuged at $5,000 \mathrm{~g}$ for 2 min, and resuspended in NaP buffer (pH 7.4) to give an absorbance at $600 \mathrm{~nm}$ of 1 . An aliquot of $300 \mu \mathrm{L}$ of the bacterial suspension was treated with increasing peptide concentrations (from 0 to $40 \mu \mathrm{M}$ ) in the Lab-Tek $^{\text {TM }}$ Chambered Cover glass systems and incubated at room temperature for $1 \mathrm{~h}$. The aggregation behavior was observed by staining with wheat germ agglutinin-Oregon Green 488 conjugate $(50 \mu \mathrm{g} / \mathrm{mL})$ by confocal laser scanning microscopy. The agglutinating activity is expressed as the minimum agglutinating concentration (MAC) of the samples tested. Each experiment was performed in triplicate.

\section{Scanning Electron Microscopy}

To perform scanning electron microscopy (SEM) analyses, B. cenocepacia LMG 18863 biofilm was incubated with increasing concentrations of GVF27 $(2.5$ to $40 \mu \mathrm{M})$ for $24 \mathrm{~h}$ at $37^{\circ} \mathrm{C}$. Following incubation, bacterial biofilm was fixed in $2.5 \%$ glutaraldehyde. Following over-night incubation, bacterial biofilm was washed three times in distilled water and then dehydrated with a graded ethanol series: $25 \%$ ethanol $(1 \times 10 \mathrm{~min}) ; 50 \%$ ethanol $(1 \times 10 \mathrm{~min}) ; 75 \%$ ethanol $(1 \times 10 \mathrm{~min}) ; 95 \%$ ethanol $(1 \times 10 \mathrm{~min}) ; 100 \%$ anhydrous ethanol $(3 \times 30 \mathrm{~min})$. Bacterial biofilm deposited onto glass substrate was sputter coated with a thin layer of Au-Pd (Sputter Coater Denton Vacuum DeskV) to allow subsequent morphological characterization using a FEI Nova NanoSEM 450 at an accelerating voltage of $5 \mathrm{kV}$ with Everhart Thornley Detector (ETD) and Through Lens Detector (TLD) at high magnification.

\section{LPS isolation}

B. cenocepacia $\mathrm{J} 2315$ cells were grown over-night in NB at $37^{\circ} \mathrm{C}$, harvested by centrifugation and freezedried. Afterwards, these cells were then submitted to the petroleum ether-chloroform-phenol (PCP) extraction method; the remaining pellet was further extracted according to the hot water-phenol method. Each phase was dialyzed against distilled water to remove phenol, freeze-dried, and then screened by SDS-PAGE to detect the presence of LPS by using silver staining procedure [46, 47]. LPS was identified in the water phase of the hot water-phenol extraction (yield $77.2 \mathrm{mg} / \mathrm{g}$ of cells). This material was further purified through an enzymatic digestion using DNAse, RNAse and proteinase $\mathrm{K}$ [48] followed by centrifugation at $6,000 \mathrm{rpm}$ for $30 \mathrm{~min}$ at $4{ }^{\circ} \mathrm{C}$. The purified LPS was isolated in the pellet (yield 15.0 $\mathrm{mg} / \mathrm{g}$ of cells).

\section{Isothermal Titration Calorimetry}


Isothermal titration calorimetry (ITC) was performed on the Low Volume NanolTC (TA Instruments-Waters LLC, New Castle, DE, USA) to determine interaction between LPSs from B. cenocepacia or E. coli and GVF27. Briefly, both GVF27 $(200 \mu \mathrm{M})$ and LPS $(0.188 \mathrm{mg} / \mathrm{ml} \sim 12,5 \mu \mathrm{M})$ were diluted in $10 \mathrm{mM}$ HEPES, $\mathrm{pH}$ 7. The chamber was filled with $164 \mu \mathrm{L}$ of LPS, and $2 \mu \mathrm{l}$ of the peptide was titrated into the chamber every 300 seconds. Experiments were performed at $37^{\circ} \mathrm{C}$ and analysed using the Nano Analyze software (TA instruments-Waters LLC). All the experiments were performed in duplicate after which calculated binding characteristics of both experiments were averaged.

\section{Fluorescence Displacement Assay}

Association of GVF27 with LPS has been determined as described in [49]. Briefly, the synthetic FAMGVF27 (1.25 mM) was added to increasing concentrations of LPSs extracted from B. cenocepacia (from 0 to $150 \mathrm{mg} / \mathrm{mL}$ ) and the fluorescence was monitored at an excitation wavelength of $495 \mathrm{~nm}$ and an emission wavelength of $520 \mathrm{~nm}$ in $5 \mathrm{mM}$ ammonium acetate ( $\mathrm{pH}$ 5.0).

\section{LPS neutralization assay by ELISA}

Anti-inflammatory effects of GVF27 were analysed in PMA differentiated and undifferentiated THP-1 cells treated with LPS. Cells were plated into 96 -well plates at a density of $2 \times 10^{4}$ cells in $100 \mu \mathrm{L}$ of medium per well. Following incubation with 5 or $20 \mu \mathrm{M}$ GVF27 and $1 \mu \mathrm{g} / \mathrm{mL}$ LPS, medium was collected to quantify cytokines levels. TNF- $a$ and MCP-1 levels in collected supernatants were determined by using human immunoassay kits (DuoSet ELISA kits, R\&D Systems, Minneapolis, MN) according to the manufacturer's instructions. Samples optical density was measured using an ELISA reader set at $450 \mathrm{~nm}$ with a wavelength correction set at $540 \mathrm{~nm}$. All experiments were performed in triplicate.

\section{Statistical analysis}

Data were analysed with GraphPad Prism, version 5.0 software (GraphPad Inc., San Diego, CA) by using Student's t-test. A $p$-value of 0.05 or less was considered statistically significant.

\section{Abbreviations}

HDP: host defence peptides; CF: Cystic Fibrosis; Bcc: Burkholderia cepacia complex; LPS: lipopolysaccharide; ITC: isothermal titration calorimetry; MHB: Muller Hinton Broth; TSA: tryptic soy agar; NB: nutrient broth; DMEM: Dulbecco's modified Eagle's medium; PBS: phosphate buffered saline; CLSM: confocal laser scanning microscopy; SEM: scanning electron microscopy; ELISA: Enzyme-Linked Immunosorbent Assay (ELISA); 5,6-FAM: 5' 6-carboxyfluorescein; RPMI: Roswell Park Memorial Institute; PMA: phorbol 12-myristate 13-acetate; PNAG: poly- $\beta 1,6-\mathrm{N}$-acetylglucosamine; PIA: polysaccharide intercellular adhesin; MTT: 3- (4,5-dimethylthiazol-2-yl) -2,5-diphenyltetrazolium bromide; TFA: Trifluoroacetic acid.

\section{Declarations}


Acknowledgments

We are deeply indebted to volunteers who devote many efforts in fundraising, in particular Gruppo di Sostegno FFC di San Giovanni Rotondo, Guadagnin srl, Delegazione FFC di Reggio Calabria, Delegazione FFC di Imola e Romagna.

Author Contributions BA, GR, AA and PE designed the study; BA, GR, DGR, VEJA, GVP, performed the experiments; $C V, F S, C R$ and NE contributed to the processing of the results; $B A$ and performed the analysis; BA, GR, PE contributed to writing of the manuscript. All the authors read and approved the final manuscript.

\section{Funding}

This study was supported by the Italian Cystic Fibrosis Foundation (grant numbers 16/2017 and 18/2018).

\section{Data availability}

All data sets generated and analysed to support the conclusion of this study is included in this article and its additional files.

Code availability

Not applicable.

\section{Corresponding Author}

Correspondence to Pizzo Elio

Ethics declarations Not applicable.

Conflict of interest No conflict of interest to declare.

\section{References}

1. Prestinaci F, Pezzotti P, Pantosti A. Antimicrobial resistance: A global multifaceted phenomenon. Pathog. Glob. Health; 2015.

2. Hutchings $M$, Truman A, Wilkinson B. Antibiotics: past, present and future. Curr. Opin. Microbiol; 2019.

3. Payne DJ, Miller LF, Findlay D, et al. Time for a change: Addressing R\&D and commercialization challenges for antibacterials. Philos Trans R Soc B Biol Sci. 2015. https://doi.org/10.1098/rstb.2014.0086.

4. Hancock REW, Haney EF, Gill EE. (2016) The immunology of host defence peptides: Beyond antimicrobial activity. Nat. Rev. Immunol. 
5. Fjell CD, Hiss JA, Hancock REW, Schneider G. (2012) Designing antimicrobial peptides: Form follows function. Nat. Rev. Drug Discov.

6. Hemshekhar M, Anaparti V, Mookherjee N. (2016) Functions of cationic host defense peptides in immunity. Pharmaceuticals.

7. Mangoni ML, Mcdermott AM, Zasloff M. Antimicrobial peptides and wound healing: Biological and therapeutic considerations. Exp Dermatol. 2016. https://doi.org/10.1111/exd.12929.

8. Park YJ, Lee SK, Jung YS, et al. Promotion of formyl peptide receptor 1-mediated neutrophil chemotactic migration by antimicrobial peptides isolated from the centipede Scolopendra subspinipes mutilans. BMB Rep. 2016. https://doi.org/10.5483/BMBRep.2016.49.9.098.

9. Veldhuizen EJA, Schneider VAF, Agustiandari $\mathrm{H}$, et al. Antimicrobial and immunomodulatory activities of PR-39 derived peptides. PLoS One. 2014. https://doi.org/10.1371/journal.pone.0095939.

10. Niyonsaba F, Ushio $H$, Nakano $N$, et al. Antimicrobial peptides human $\beta$-defensins stimulate epidermal keratinocyte migration, proliferation and production of proinflammatory cytokines and chemokines. J Invest Dermatol. 2007. https://doi.org/10.1038/sj.jid.5700599.

11. Oppenheim JJ, Biragyn A, Kwak LW, Yang D. Roles of antimicrobial peptides such as defensins in innate and adaptive immunity. In: Annals of the Rheumatic Diseases; 2003.

12. Lewies A, Du Plessis LH, Wentzel JF. (2019) Antimicrobial Peptides: the Achilles' Heel of Antibiotic Resistance? Probiotics Antimicrob Proteins. https://doi.org/10.1007/s12602-018-9465-0.

13. Sun E, Belanger CR, Haney EF, Hancock REW. Host defense (antimicrobial) peptides. Biotechnology: In: Peptide Applications in Biomedicine; 2018.

14. Drevinek P, Mahenthiralingam E. Burkholderia cenocepacia in cystic fibrosis: Epidemiology and molecular mechanisms of virulence. Clin Microbiol Infect. 2010;16:821-30. https://doi.org/10.1111/j.1469-0691.2010.03237.x.

15. Mahenthiralingam E, Urban TA, Goldberg JB. (2005) The multifarious, multireplicon Burkholderia cepacia complex. Nat. Rev. Microbiol.

16. Melo Coutinho H. (2007) Burkholderia cepacia complex: Virulence characteristics, importance and relationship with cystic fibrosis. Indian J. Med. Sci.

17. Rhodes KA, Schweizer HP. Antibiotic resistance in Burkholderia species. Drug Resist Updat. 2016. https://doi.org/10.1016/j.drup.2016.07.003.

18. Podnecky NL, Rhodes KA, Schweizer HP. Efflux pump-mediated drug resistance in burkholderia. Front Microbiol. 2015. https://doi.org/10.3389/fmicb.2015.00305.

19. Uehlinger S, Schwager S, Bernier SP, et al. Identification of specific and universal virulence factors in Burkholderia cenocepacia strains by using multiple infection hosts. Infect Immun. 2009. https://doi.org/10.1128/IAI.00398-09.

20. Loutet SA, Valvano MA. A decade of Burkholderia cenocepacia virulence determinant research. Infect. Immun; 2010. 
21. Shommu NS, Vogel HJ, Storey DG. Potential of metabolomics to reveal Burkholderia cepacia complex pathogenesis and antibiotic resistance. Front Microbiol. 2015. https://doi.org/10.3389/fmicb.2015.00668.

22. McClean S, Callaghan M. Burkholderia cepacia complex: Epithelial cell-pathogen confrontations and potential for therapeutic intervention. J Med Microbiol. 2009;58:1-12. https://doi.org/10.1099/jmm.0.47788-0.

23. Kooi C, Subsin B, Chen R, et al. Burkholderia cenocepacia ZmpB is a broad-specificity zinc metalloprotease involved in virulence. Infect Immun. 2006. https://doi.org/10.1128/IAI.00297-06.

24. Mullen T, Markey K, Murphy $P$, et al. Role of lipase in Burkholderia cepacia complex (Bcc) invasion of lung epithelial cells. Eur J Clin Microbiol Infect Dis. 2007. https://doi.org/10.1007/s10096-007-03852.

25. Ganesan S, Sajjan US. Host evasion by Burkholderia cenocepacia. Front. Cell. Infect. Microbiol; 2011.

26. Shaw D, Poxton IR, Govan JRW. Biological activity of Burkholderia (Pseudomonas) cepacia lipopolysaccharide. FEMS Immunol Med Microbiol. 1995. https://doi.org/10.1016/09288244(95)00012-V.

27. De Soyza A, Silipo A, Lanzetta R, et al. Chemical and biological features of Burkholderia cepacia complex lipopolysaccharides. Innate Immun. 2008;14:127-44. https://doi.org/10.1177/1753425908093984.

28. Norris MH, Schweizer HP, Tuanyok A. Structural diversity of Burkholderia pseudomallei lipopolysaccharides affects innate immune signaling. PLoS Negl Trop Dis. 2017. https://doi.org/10.1371/journal.pntd.0005571.

29. Ieranò T, Cescutti P, Leone MR, et al. The lipid A of Burkholderia multivorans C1576 smooth-type lipopolysaccharide and its pro-inflammatory activity in a cystic fibrosis airways model. Innate Immun. 2010. https://doi.org/10.1177/1753425909347400.

30. Hollaus R, Ittig S, Hofinger A, et al. Chemical synthesis of burkholderia lipid a modified with glycosyl phosphodiester-linked 4-amino-4-deoxy- $\beta$-L-arabinose and its immunomodulatory potential. Chem - A Eur J. 2014;21:4102-14. https://doi.org/10.1002/chem.201406058.

31. Pane K, Durante L, Crescenzi $O$, et al. Antimicrobial potency of cationic antimicrobial peptides can be predicted from their amino acid composition: Application to the detection of "cryptic" antimicrobial peptides. J Theor Biol. 2017. https://doi.org/10.1016/j.jtbi.2017.02.012.

32. Pizzo E, Cafaro V, Di Donato A, Notomista E. (2018) Cryptic antimicrobial peptides: Identification methods and current knowledge of their immunomodulatory properties. Curr Pharm Des 24:. https://doi.org/10.2174/1381612824666180327165012.

33. Bosso A, Di Maro A, Cafaro V, et al. Enzymes as a Reservoir of Host Defence Peptides. Curr Top Med Chem. 2020;20:1310-23. https://doi.org/10.2174/1568026620666200327173815.

34. Bosso A, Pirone L, Gaglione R, et al (2017) A new cryptic host defense peptide identified in human 11hydroxysteroid dehydrogenase- $1 \beta$-like: from in silico identification to experimental evidence. Biochim Biophys Acta - Gen Subj 1861:. https://doi.org/10.1016/j.bbagen.2017.04.009. 
35. Yakandawala N, Gawande PV, LoVetri K, et al. Characterization of the poly- $\beta-1,6-N$-acetylglucosamine polysaccharide component of Burkholderia biofilms. Appl Environ Microbiol. 2011;77:8303-9. https://doi.org/10.1128/AEM.05814-11.

36. Di Lorenzo F, Kubik $Ł$, Oblak A, et al. Activation of Human Toll-like receptor 4 (TLR4)-myeloid differentiation factor 2 (MD-2) by hypoacylated lipopolysaccharide from a clinical isolate of Burkholderia cenocepacia. J Biol Chem. 2015. https://doi.org/10.1074/jbc.M115.649087.

37. Speert DP, Henry D, Vandamme P, et al (2002) Epidemiology of Burkholderia cepacia complex in patients with cystic fibrosis, Canada. Emerg Infect Dis 8:. https://doi.org/10.3201/eid0802.010163.

38. Loutet SA, Valvano MA. Extreme Antimicrobial Peptide and Polymyxin B Resistance in the Genus Burkholderia. Front Microbiol. 2011. https://doi.org/10.3389/fmicb.2011.00159.

39. Van Acker H, Sass A, Bazzini S, et al. Biofilm-Grown Burkholderia cepacia Complex Cells Survive Antibiotic Treatment by Avoiding Production of Reactive Oxygen Species. PLoS One. 2013;8:1-12. https://doi.org/10.1371/journal.pone.0058943.

40. Hoffman LR, D'Argenio DA, MacCoss MJ, et al. Aminoglycoside antibiotics induce bacterial biofilm formation. Nature. 2005;436:1171-5. https://doi.org/10.1038/nature03912.

41. Linares JF, Gustafsson I, Baquero F, Martinez JL. Antibiotics as intermicrobiol signaling agents instead of weapons. Proc Natl Acad Sci U S A. 2006;103:19484-9. https://doi.org/10.1073/pnas.0608949103.

42. Cunha MV, Leitão JH, Mahenthiralingam E, et al. Molecular analysis of Burkholderia cepacia complex isolates from a Portuguese cystic fibrosis center: A 7-year study. J Clin Microbiol. 2003;41:4113-20. https://doi.org/10.1128/JCM.41.9.4113-4120.2003.

43. Yakandawala N, Gawande PV, LoVetri K, et al. Characterization of the poly- $\beta-1,6-N$-acetylglucosamine polysaccharide component of Burkholderia biofilms. Appl Environ Microbiol. 2011. https://doi.org/10.1128/AEM.05814-11.

44. Wiegand I, Hilpert K, Hancock REW. Agar and broth dilution methods to determine the minimal inhibitory concentration (MIC) of antimicrobial substances. Nat Protoc. 2008. https://doi.org/10.1038/nprot.2007.521.

45. Gaglione R, Dell'Olmo E, Bosso A, et al (2017) Novel human bioactive peptides identified in Apolipoprotein B: Evaluation of their therapeutic potential. Biochem Pharmacol 130:. https://doi.org/10.1016/j.bcp.2017.01.009.

46. Kittelberger R, Hilbink F. Sensitive silver-staining detection of bacterial lipopolysaccharides in polyacrylamide gels. J Biochem Biophys Methods. 1993. https://doi.org/10.1016/0165022X(93)90024-I.

47. Tsai $C M$, Frasch CE. A sensitive silver stain for detecting lipopolysaccharides in polyacrylamide gels. Anal Biochem. 1982. https://doi.org/10.1016/0003-2697(82)90673-X.

48. De Castro $\mathrm{C}$, Parrilli $\mathrm{M}$, Holst $\mathrm{O}$, Molinaro A. Microbe-associated molecular patterns in innate immunity. Extraction and chemical analysis of gram-negative bacterial lipopolysaccharides. In: Methods in Enzymology; 2010. 
49. Mohanram $\mathrm{H}$, Bhattacharjya $\mathrm{S}$. Resurrecting inactive antimicrobial peptides from the lipopolysaccharide trap. Antimicrob Agents Chemother. 2014. https://doi.org/10.1128/AAC.0232113.

\section{Tables}

Table 1. Sequences of GVF27 and LL-37 peptides.

\begin{tabular}{|lc|}
\hline Peptide & Sequence \\
\hline GVF27 & ${ }^{1}$ GVFYPWRFRLLCLLRRWLPRPRAWFIR ${ }^{27}$ \\
\hline LL-37 & ${ }^{1}$ LLGDFFRKSKEKIGKEFKRIVQRIKDFLRNLVPRTES ${ }^{37}$ \\
\hline
\end{tabular}

Table 2. Minimum Inhibitory Concentration values (MIC, $\mu M$ ) determined for GVF27, FAM-GVF27 and LL37 on B. cenocepacia LMG 18863 and B. multivorans LMG 17582. LL-37 was used as reference human antimicrobial peptide. FAM-GVF27 is 5,6-FAM fluorescently labelled GVF27 used in experiments described in the main text (see page 10). Ciprofloxacin is the quinolone antibiotic used in synergism experiments described in the main text (see page 11). MIC values were obtained from a minimum of three independent experiments.

\begin{tabular}{lllll}
\multicolumn{5}{l}{ MIC (mM) } \\
Bcc strain & GVF27 FAM-GVF27 LL-37 Ciprofloxacin
\end{tabular}

$\begin{array}{llllll}\text { Burkholderia cenocepacia LMG } 18863 & 40 & 40 & 5 & 2.5\end{array}$

$\begin{array}{lllll}\text { Burkholderia multivorans LMG } 17582 & 10 & 10 & 10 & 1.2\end{array}$

\section{Figures}



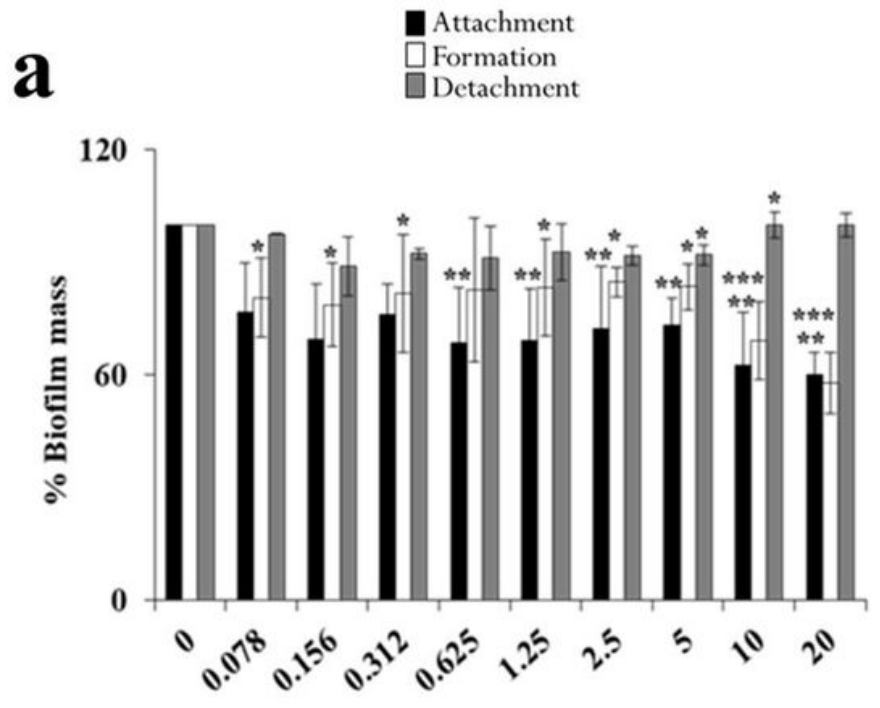

GVF27 ( $\mu$ M) b

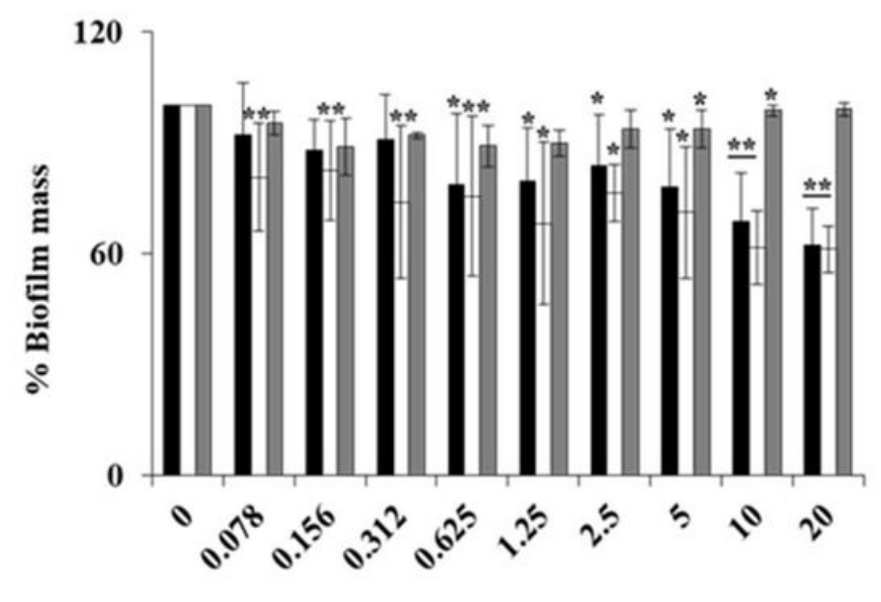

GVF27 ( $\mu$ M)

Figure 1

Anti-biofilm activity of GVF27 on B. cenocepacia LMG 18863 (A) and B. multivorans LMG 17582 (B) strains. The effects of increasing concentrations of peptide were evaluated either on biofilm attachment (black bars), biofilm formation (white bars) or on pre-formed biofilm (grey bars). Biofilm was stained with crystal violet and measured at $600 \mathrm{~nm}$. Data represent the mean ( \pm standard deviation, SD) of at least three independent experiments, each one carried out with triplicate determinations. ${ }^{\star} P<0.05,{ }^{*} P<0.01$, or ${ }^{\star * *} \mathrm{P}<0.001$ were obtained for control versus treated samples. 
a

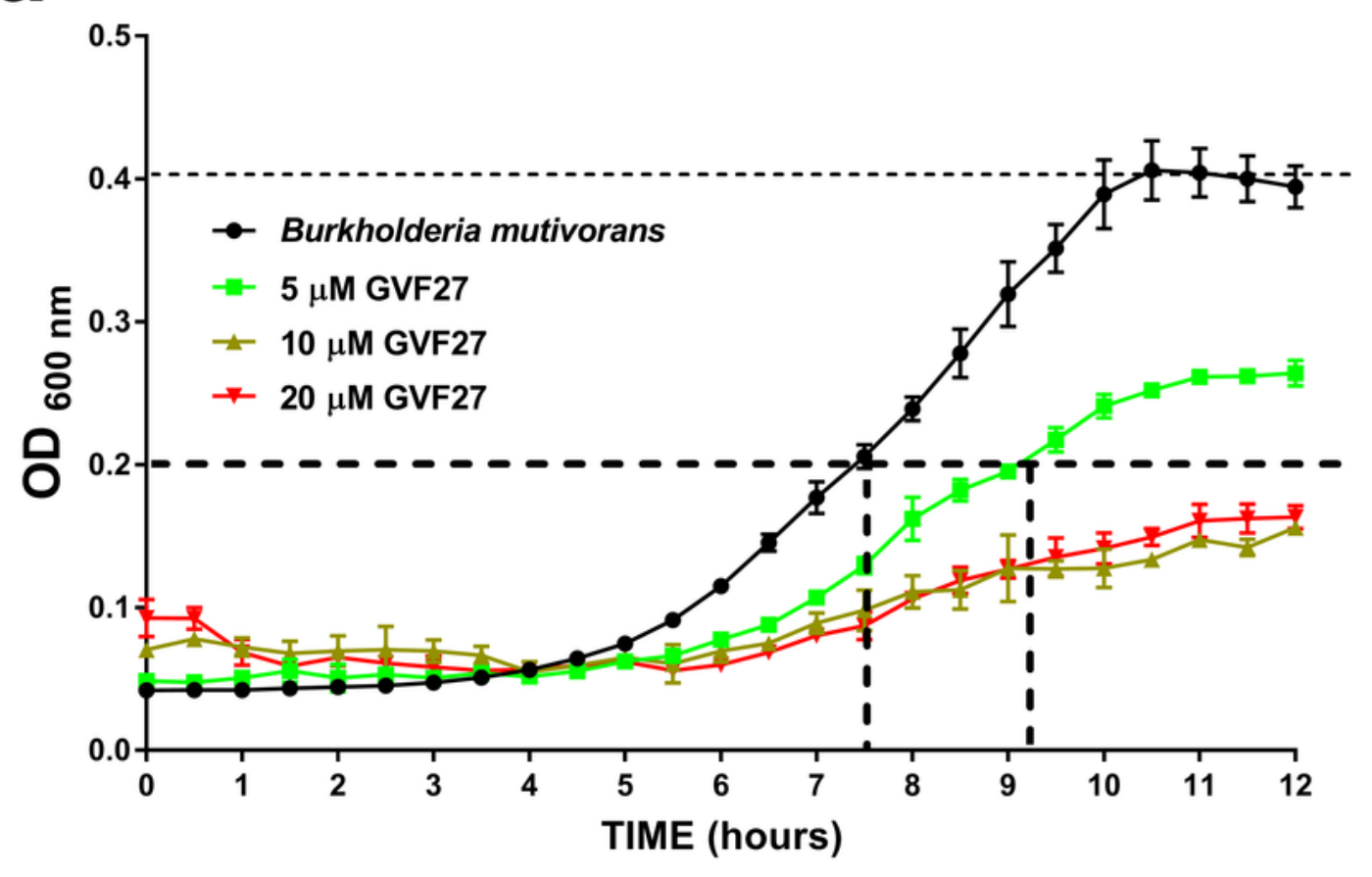

b

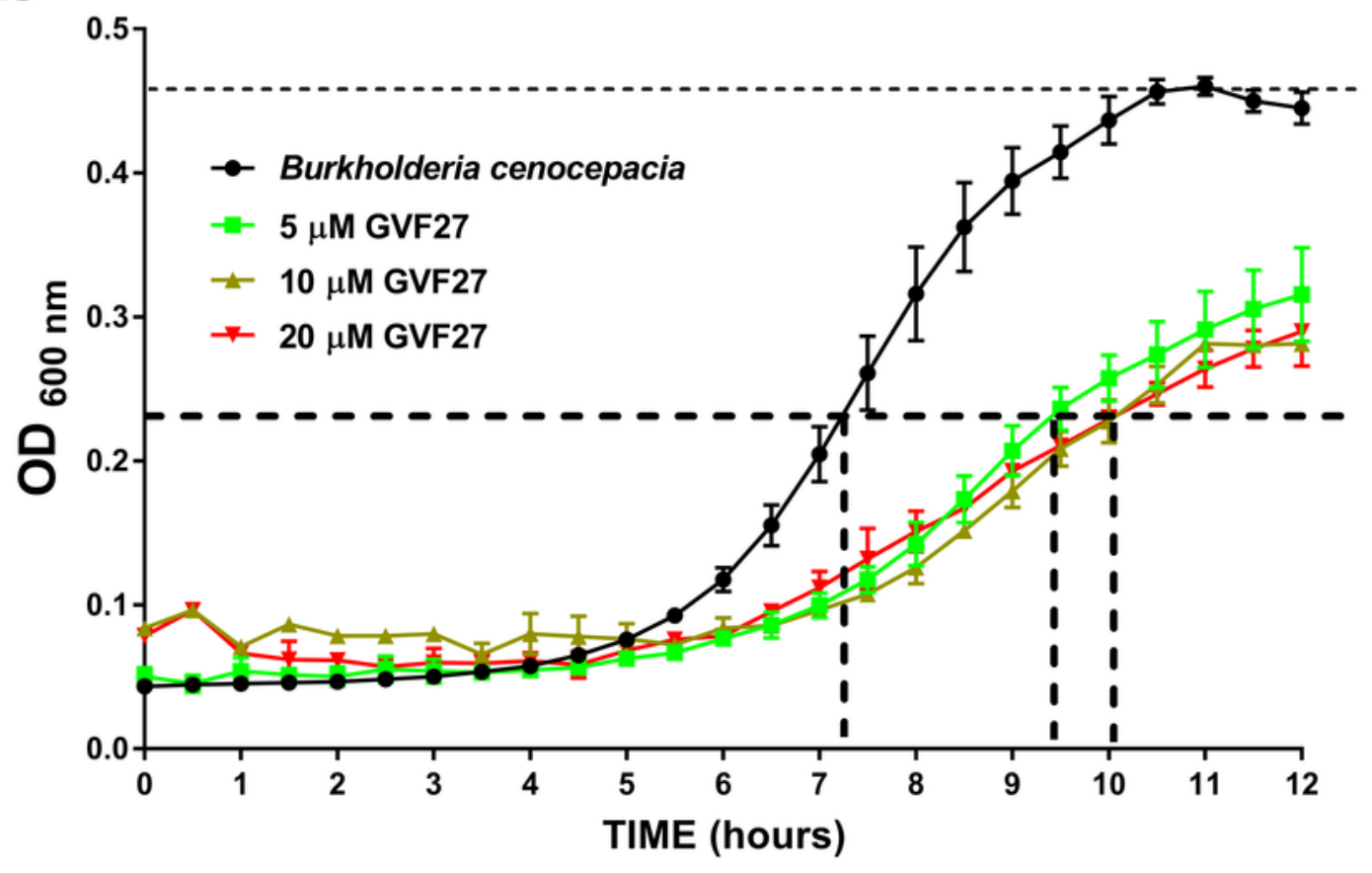

Figure 2

Time-killing curves obtained for GVF27 tested on B. cenocepacia LMG 18863 and B. multivorans LMG 17582. Three doubling dilutions are plotted; the highest concentration (red line) corresponds to $2 \times \mathrm{MIC} 100$ of B. multivorans LMG 17582 and to 0.5 x MIC100 of B. cenocepacia LMG 18863, respectively. GVF27 was added at time point 0 and monitored until $12 \mathrm{~h}$. Bacterial growth delay was defined as the delay in hours for peptide-treated bacteria to reach half of the maximum OD of the untreated control (OD $1 / 2)$. 
GVF27 $(5 \mu \mathrm{M})$ delay of 1.45 hours the growth of B. multivorans and of 2.5 hours the growth of B. cenocepacia. At higher doses $(10$ and $20 \mu \mathrm{M})$, GVF27 prevents reaching the OD $1 \frac{1}{2}$ of B. multivorans while, at the same doses, it is not capable to further delay the growth of B. cenocepacia.
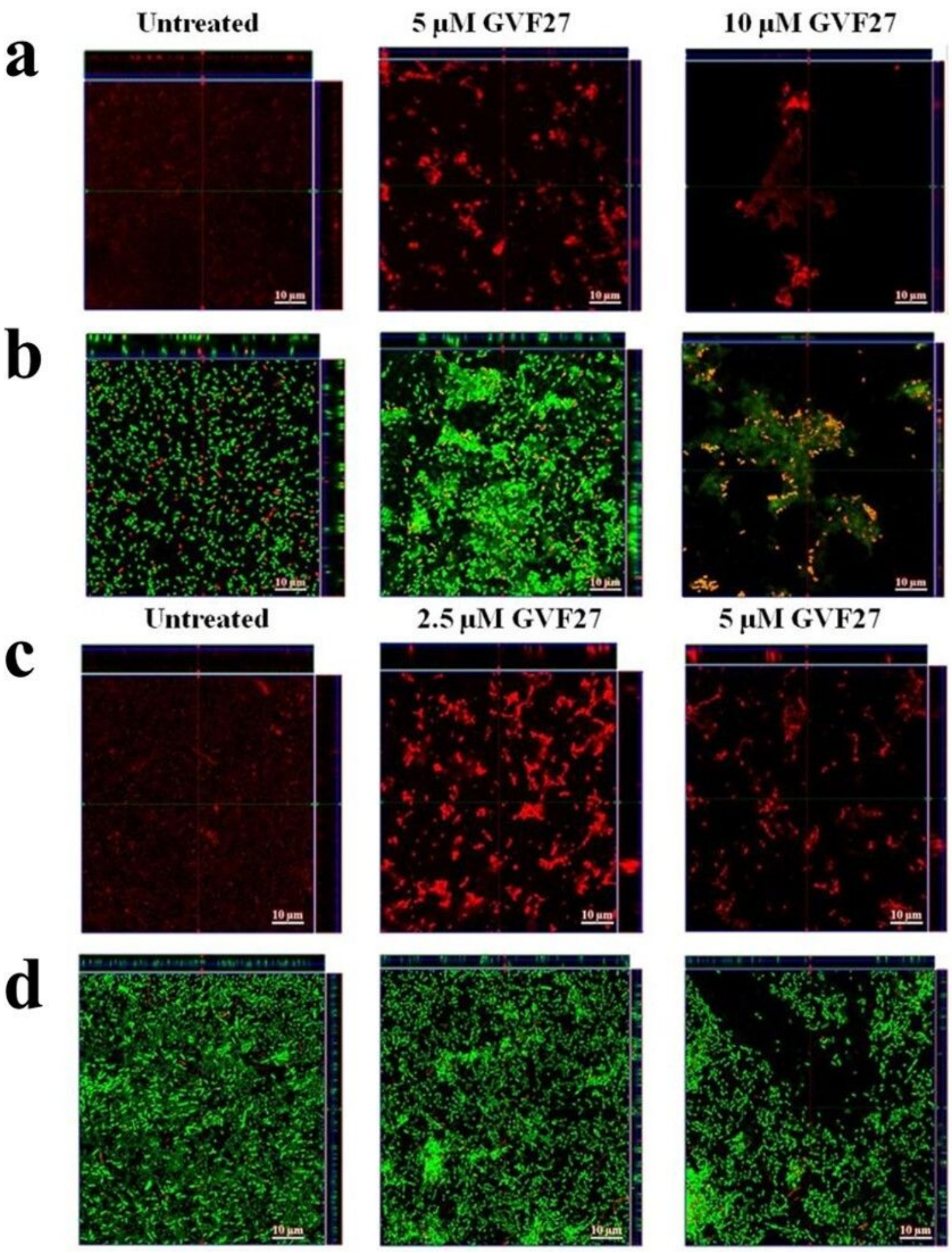

Figure 3

Anti-biofilm activity of GVF27 peptide on the attachment of B. cenocepacia LMG 18863 (Panels A and B) and B. multivorans LMG 17582(Panels C and D) biofilm. Biofilm cells were stained by using FilmTracer ${ }^{\mathrm{TM}}$ 
SYPRO $^{\text {TM }}$ Ruby Biofilm Matrix Stain (Invitrogen ${ }^{T M}$ ) (A, C) and LIVE/DEAD BacLight bacterial viability kit (Molecular Probes, Eugene, OR) containing 1:1 ratio of Syto-9 (green fluorescence, all cells) and propidium iodide ( $\mathrm{Pl}$; red fluorescence, dead cells) $(\mathrm{B}, \mathrm{D})$. Scale bar corresponds to $10 \mu \mathrm{m}$ in all the cases.
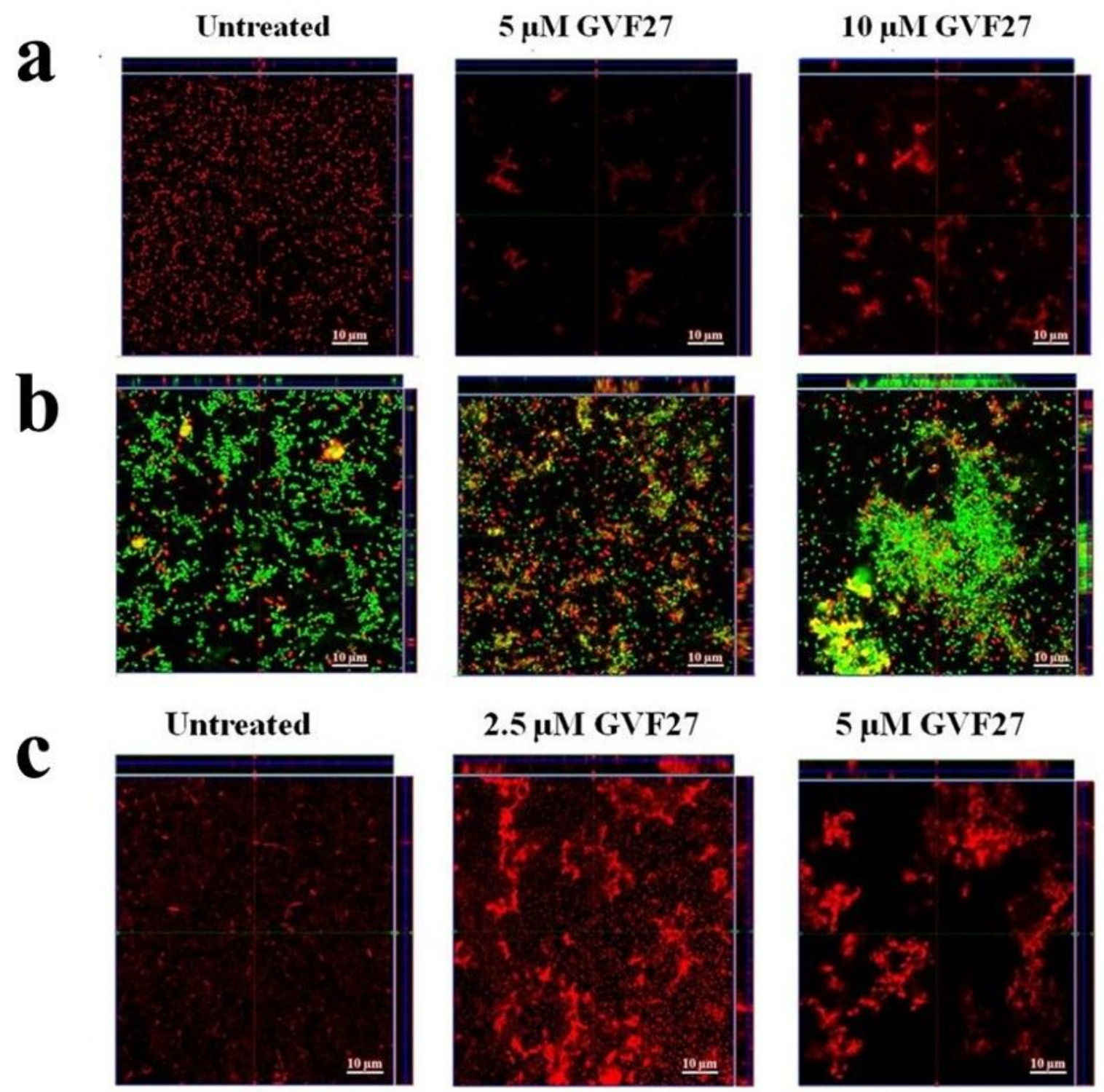

\section{$5 \mu \mathrm{M} \mathrm{GVF27}$}
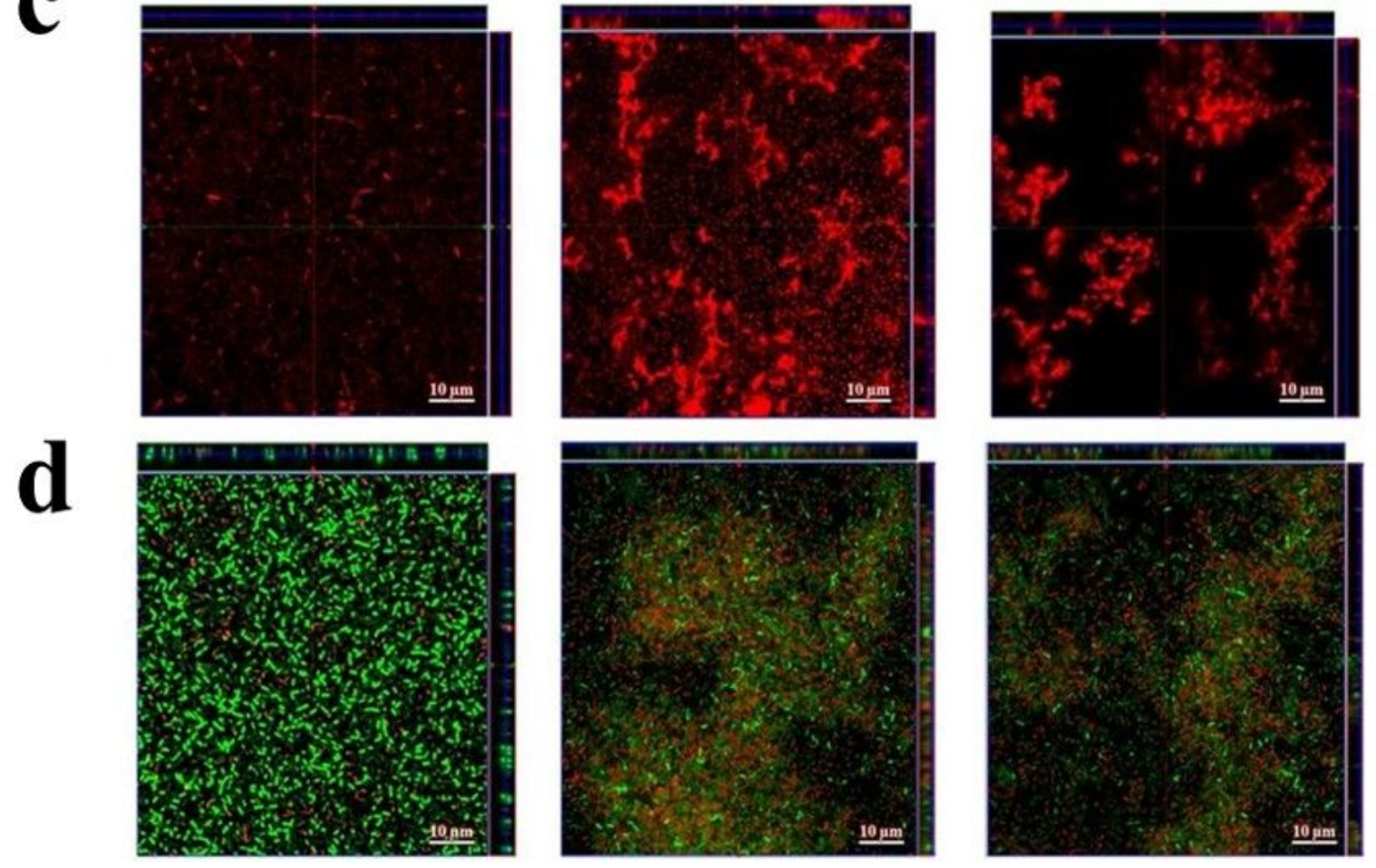

Figure 4

Anti-biofilm activity of GVF27 peptide on the formation of B. cenocepacia LMG 18863 (Panels A and B) and B. multivorans LMG 17582(Panels C and D) biofilm. Biofilm cells were stained by using FilmTracer ${ }^{\text {TM }}$ 
SYPRO $^{\text {TM }}$ Ruby Biofilm Matrix Stain (Invitrogen ${ }^{\text {TM }}$ ) (a, c) and LIVE/DEAD BacLight bacterial viability kit (Molecular Probes, Eugene, OR) containing 1:1 ratio of Syto-9 (green fluorescence, all cells) and propidium iodide (PI; red fluorescence, dead cells) (b, d). Scale bar corresponds to $10 \mu \mathrm{m}$ in all the cases.

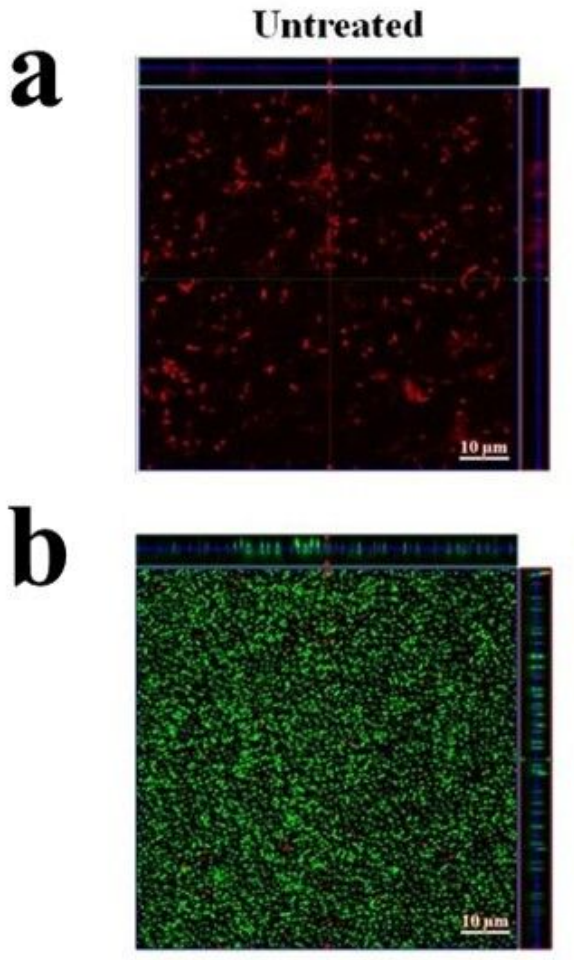

Untreated

c
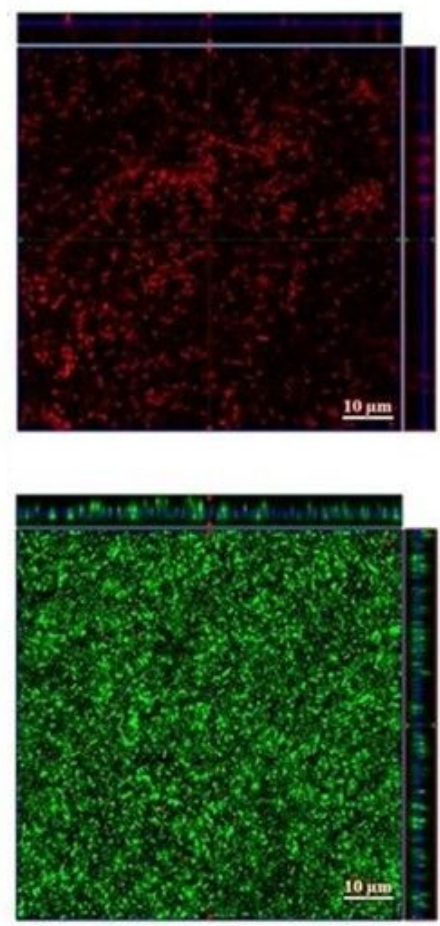

$5 \mu$ MVF27
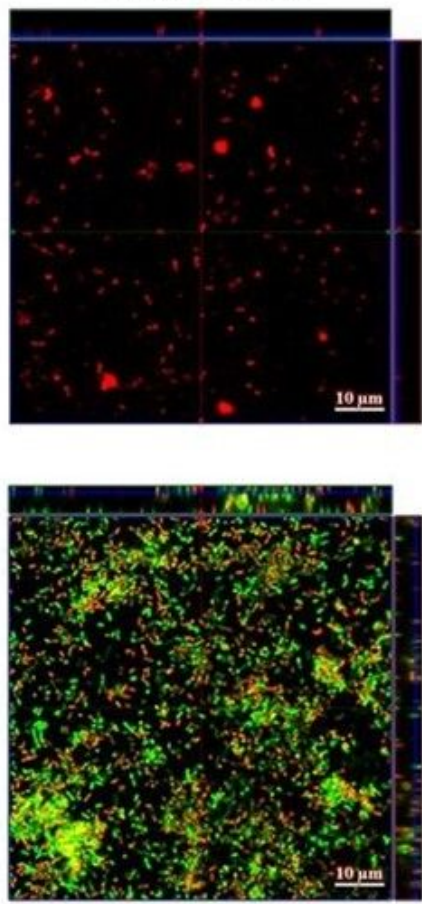

$2.5 \mu M$ GVF27
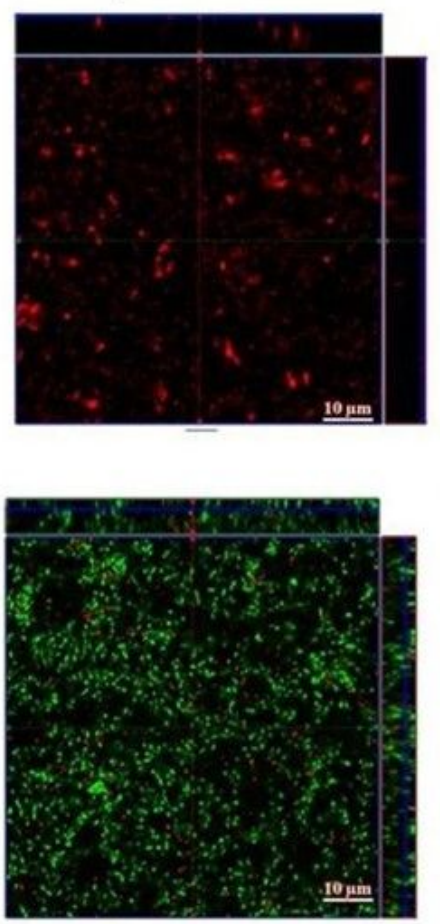

$10 \mu M$ GVF27
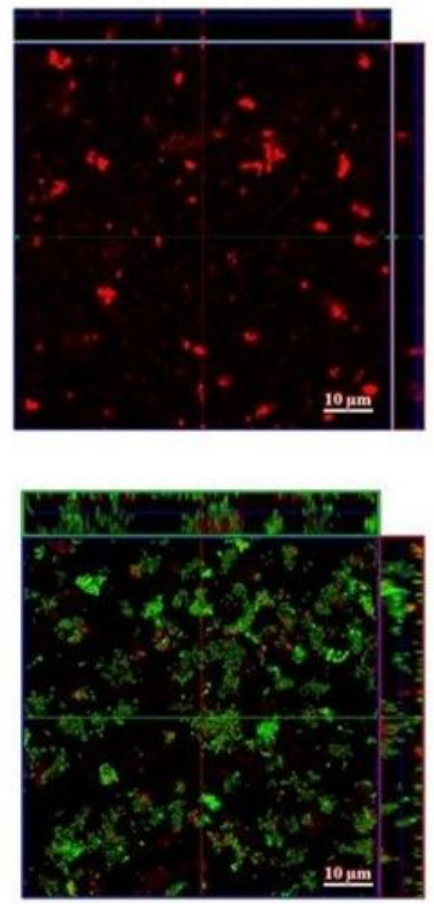

\section{$5 \mu \mathrm{M} \mathrm{GVF27}$}
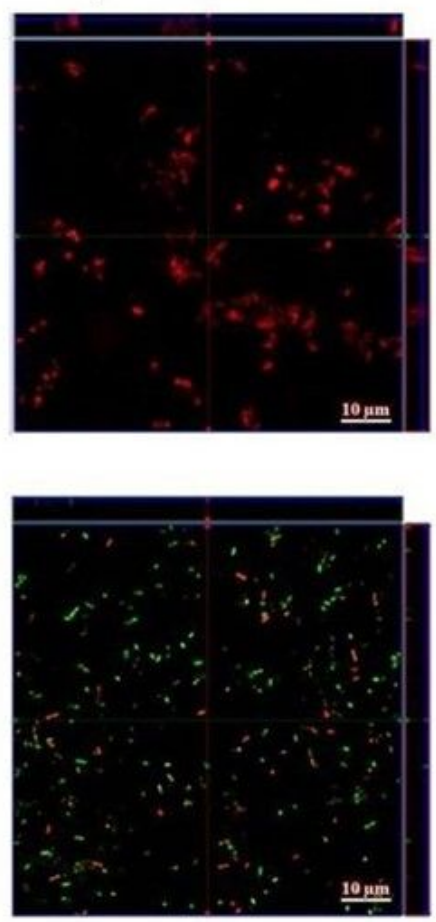

Figure 5

Anti-biofilm activity of GVF27 peptide on preformed biofilm B. cenocepacia LMG $18863(\mathrm{a}, \mathrm{b})$ and B. multivorans LMG 17582 (c, d) pre-formed biofilm by CLSM imaging. Biofilm cells were stained by using 
LIVE/DEAD BacLight bacterial viability kit (Molecular Probes, Eugene, OR) containing 1:1 ratio of Syto-9 (green fluorescence, all cells) and propidium iodide (Pl; red fluorescence, dead cells) (c, d) and FilmTracer ${ }^{\text {TM }}$ SYPRO ${ }^{\text {TM }}$ Ruby Biofilm Matrix Stain (Invitrogen ${ }^{\text {TM }}$ ) (A, B). Scale bar corresponds to $10 \mu \mathrm{m}$ in all the cases.

a
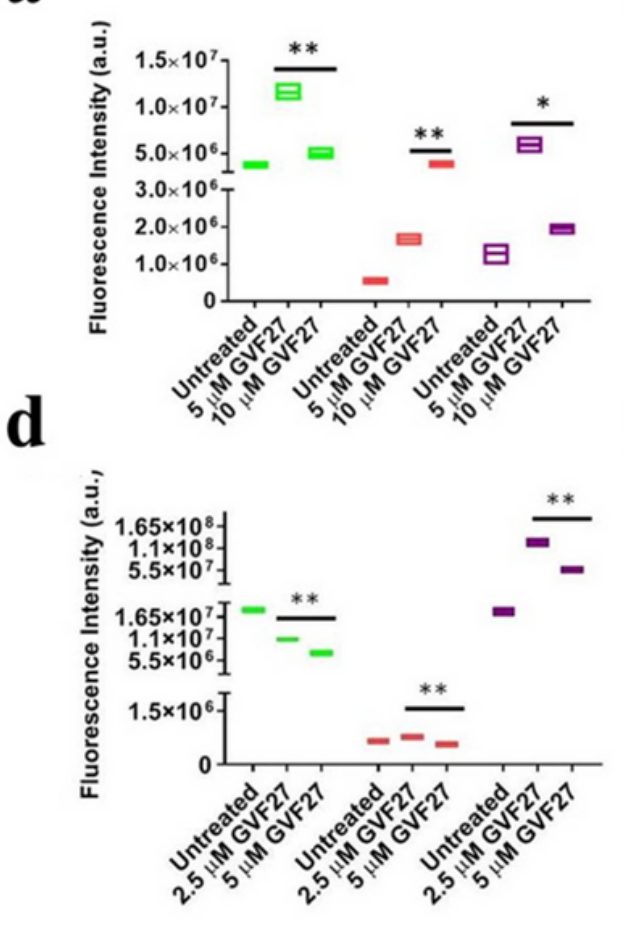

g

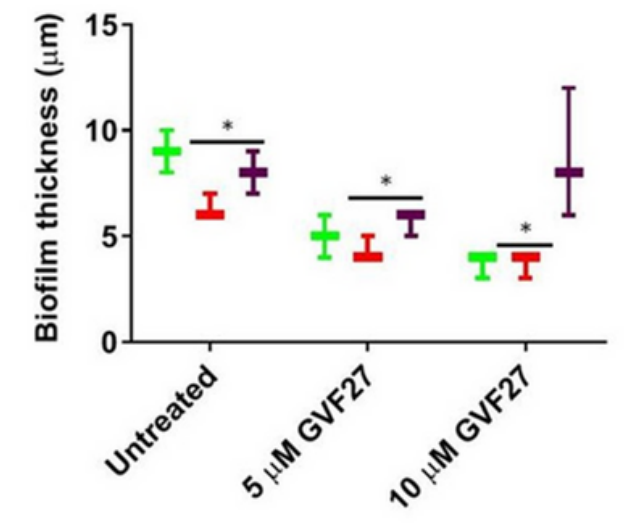

b
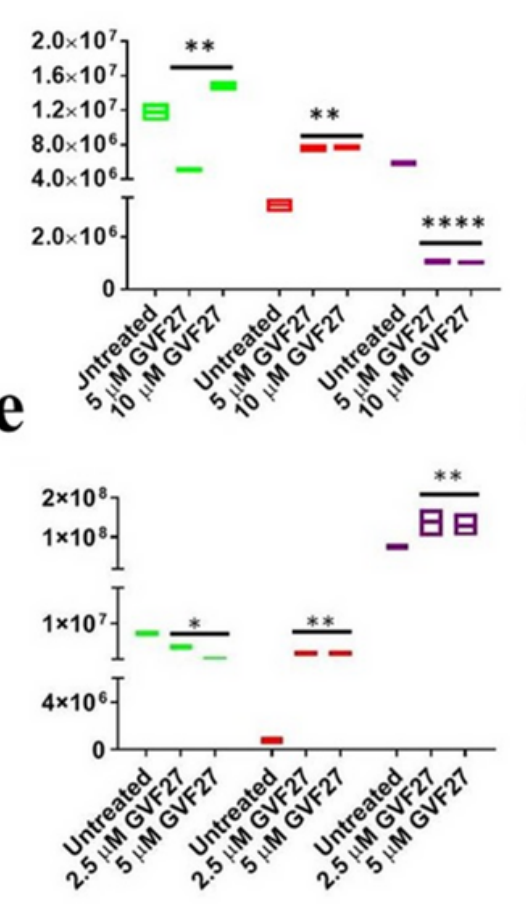

c
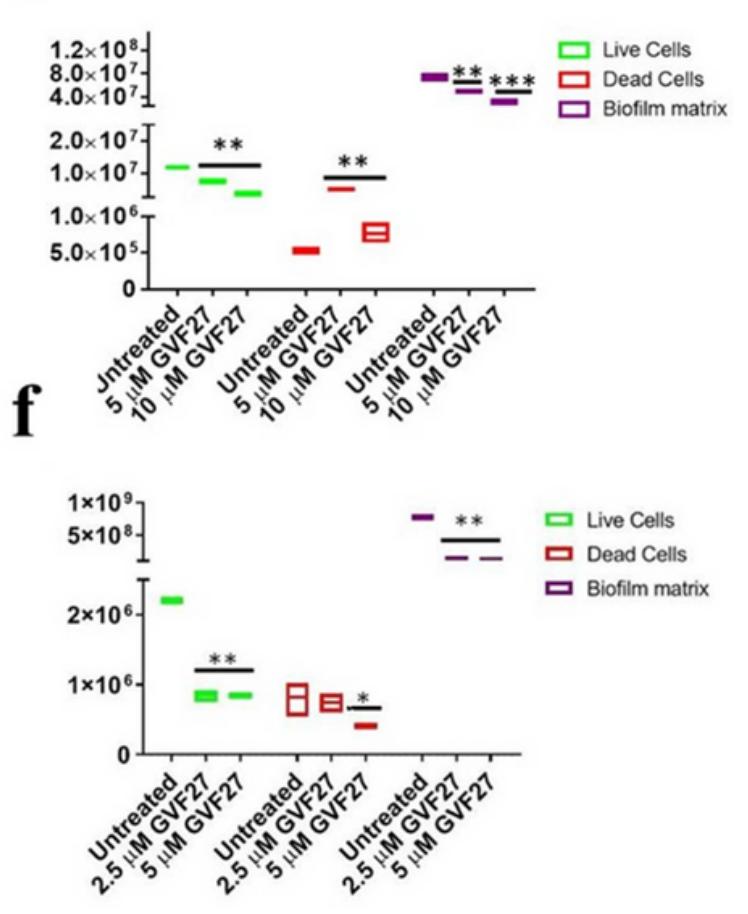

Figure 6

CLSM fluorescence analysis of the effects of GVF27 on B. cenocepacia LMG 18863 biofilm (a, attachment, b, formation, c, detachment) and B. multivorans LMG 17582 biofilm (d, attachment, e, formation, $f$, detachment). Fluorescence intensity of Syto-9, propidium iodide and Sypro Ruby Biofilm Matrix Stain were measured by using Zen Lite 2.3 software. Images are 3D projections of biofilm structure obtained by two independent experiments analysed per peptide concentration (with triple intraexperimental acquisitions). ${ }^{*}<0.05,{ }^{*} \mathrm{P}<0.01$ and ${ }^{*} * \mathrm{P}<0.001$ for treated versus control samples. 
Analysis of the effects of GVF27 peptide on B. cenocepacia LMG 18863 (panel g) and on B. multivorans LMG 17582 (panel h) biofilm thickness (green, attachment; red, formation; purple, detachment). Images are 3D projections of biofilm structure obtained by two independent experiments with triple intraexperimental acquisitions. ${ }^{*} \mathrm{P}<0.05$ and ${ }^{*} \mathrm{P}<0.01$ for treated versus control samples.

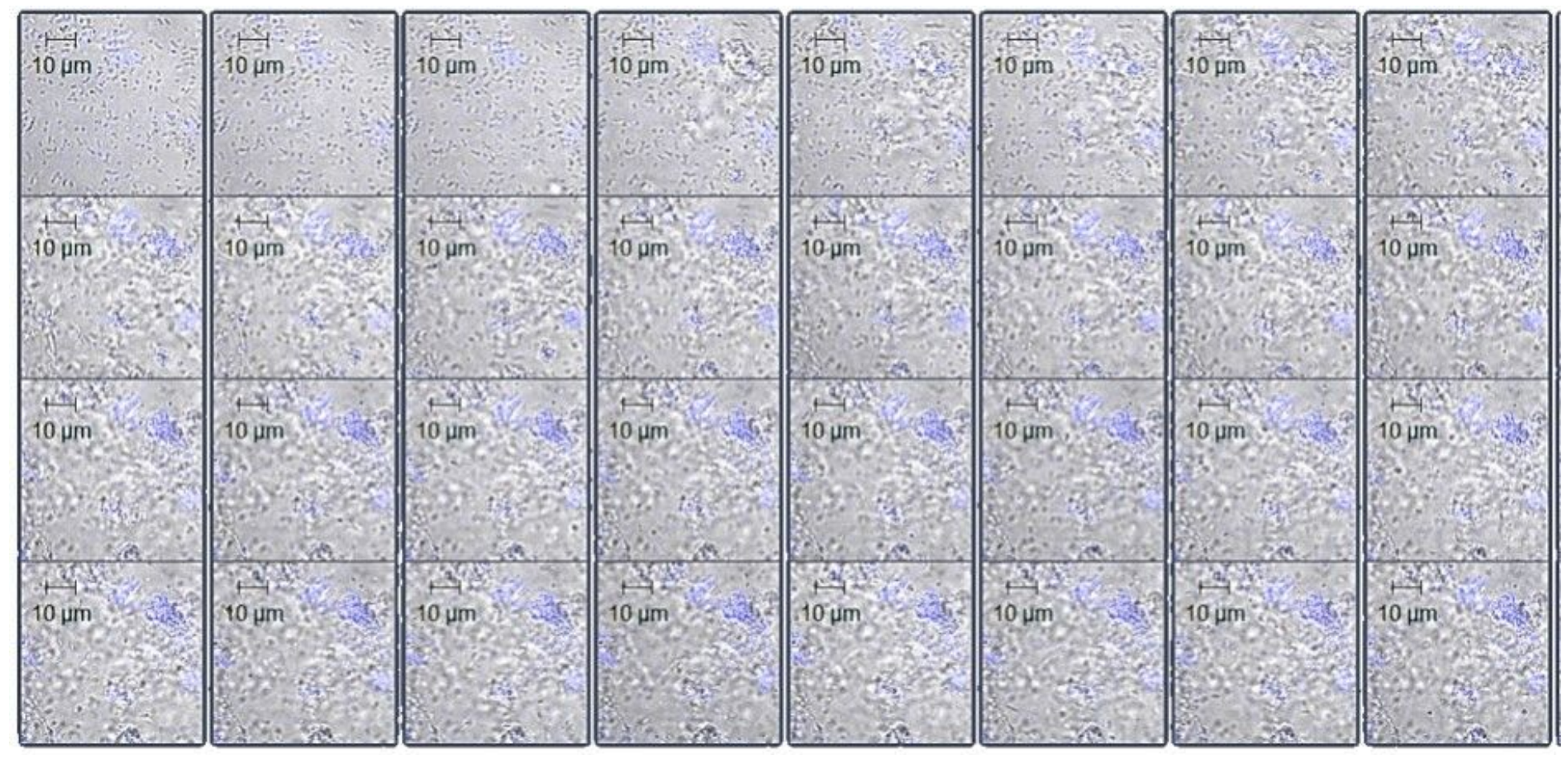

\section{Figure 7}

Time course analysis of $5 \mu \mathrm{M}$ FAM-GVF27 interaction with B. cenocepacia LMG 18863 biofilm (0-240 minutes, 1 acquisition/7.5 min). See video clip S1
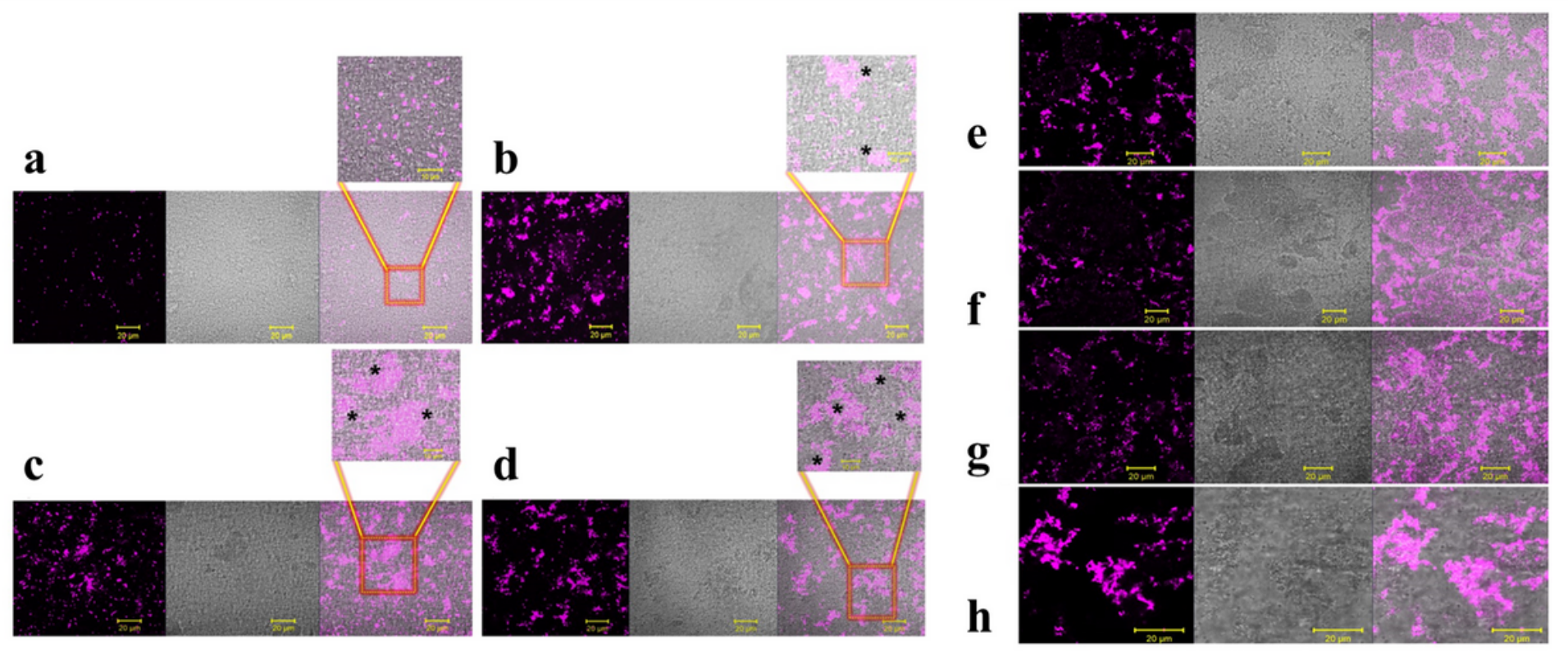

Figure 8 
Analysis of GVF27 effects on B. cenocepacia LMG 18863 planktonic cells agglutination by CLSM. The biofilm was incubated in the absence (a) or in the presence of 0.625 (b), 1.25 (c) or 2.5 (d) $\mu \mathrm{M}$ peptide and stained with wheat germ agglutinin-Oregon Green 488 conjugate. A magnification of each section is shown on the top of the images. Scale bar corresponds to $10 \mu \mathrm{m}$ or $20 \mu \mathrm{m}$. Analysis of GVF27 effects on B. cenocepacia LMG 18863 biofilm agglutination by CLSM. The biofilm was incubated in the presence of 5 (e), $10(\mathrm{f}), 20(\mathrm{~g})$ or $40 \mu \mathrm{M}$ peptide $(\mathrm{h})$ and stained with wheat germ agglutinin-Oregon Green 488 conjugate. Scale bar corresponds to $20 \mu \mathrm{m}$ in all the cases.
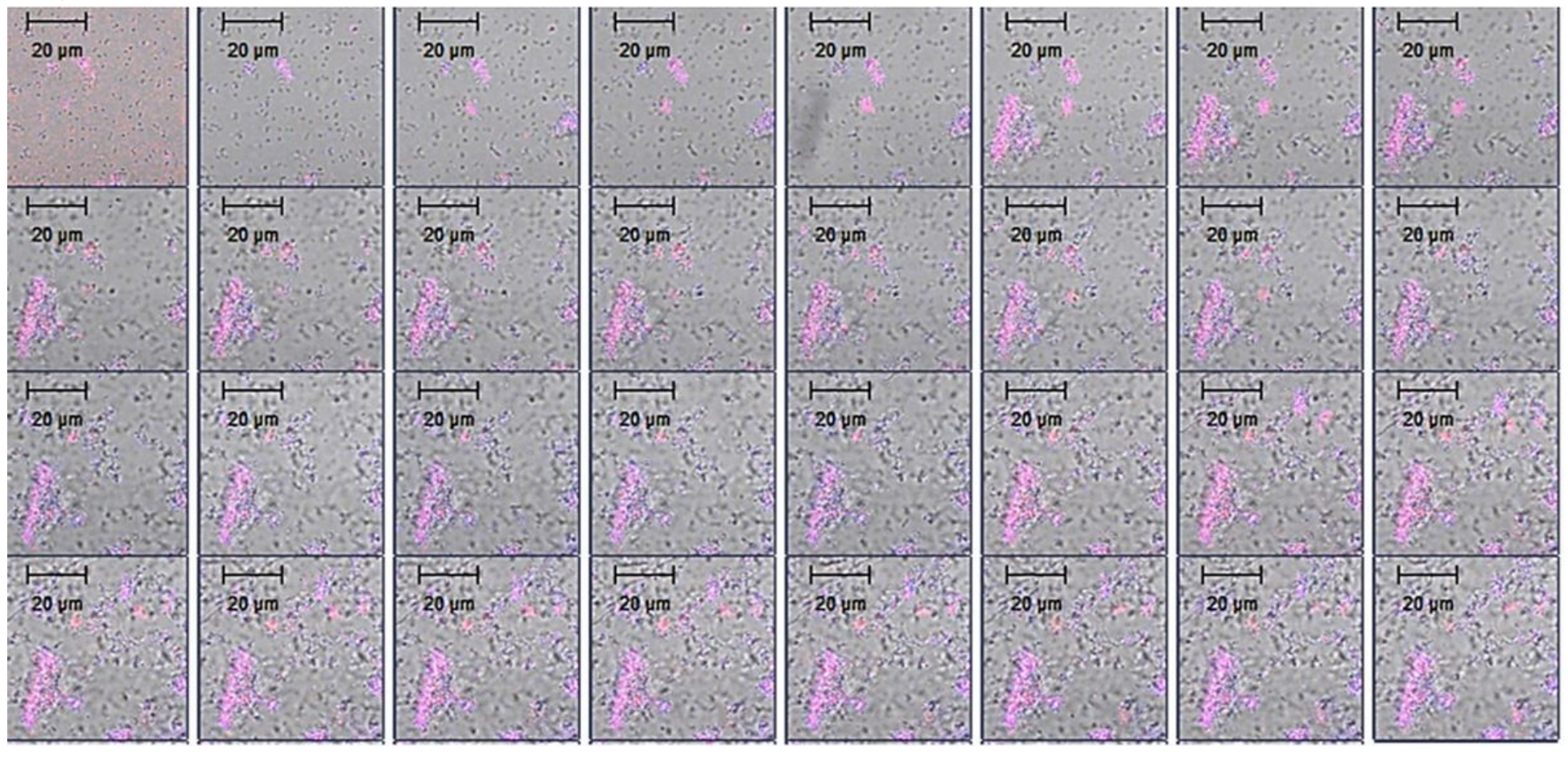

\section{Figure 9}

Time course analysis of $5 \mu \mathrm{M}$ labelled FAM-GVF27 (blue) and FilmTracer ${ }^{\mathrm{TM}}$ SYPRO ${ }^{\mathrm{TM}}$ Ruby Biofilm Matrix Stain (red) in the presence of B. cenocepacia LMG 18863 biofilm (0-240 minutes, 1 acquisition/7.5 min). See video clip S2 

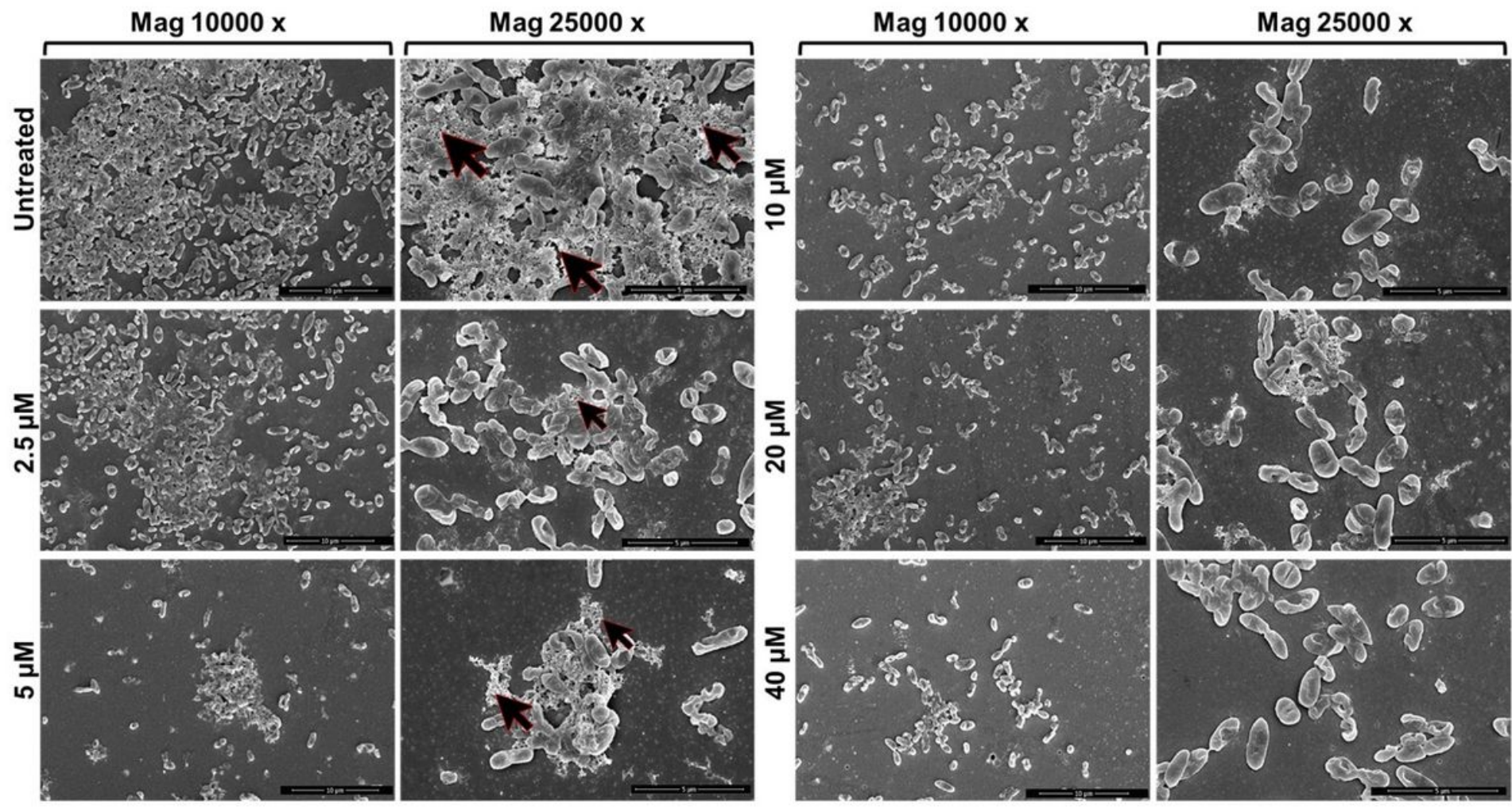

Figure 10

Scanning electron micrographs of biofilm formation (4h) of B. cenocepacia LMG 18863 in the presence of increasing concentrations of GVF27. The magnification scale is shown at the bottom of each micrograph. Black arrows indicate extracellular biofilm matrix. 

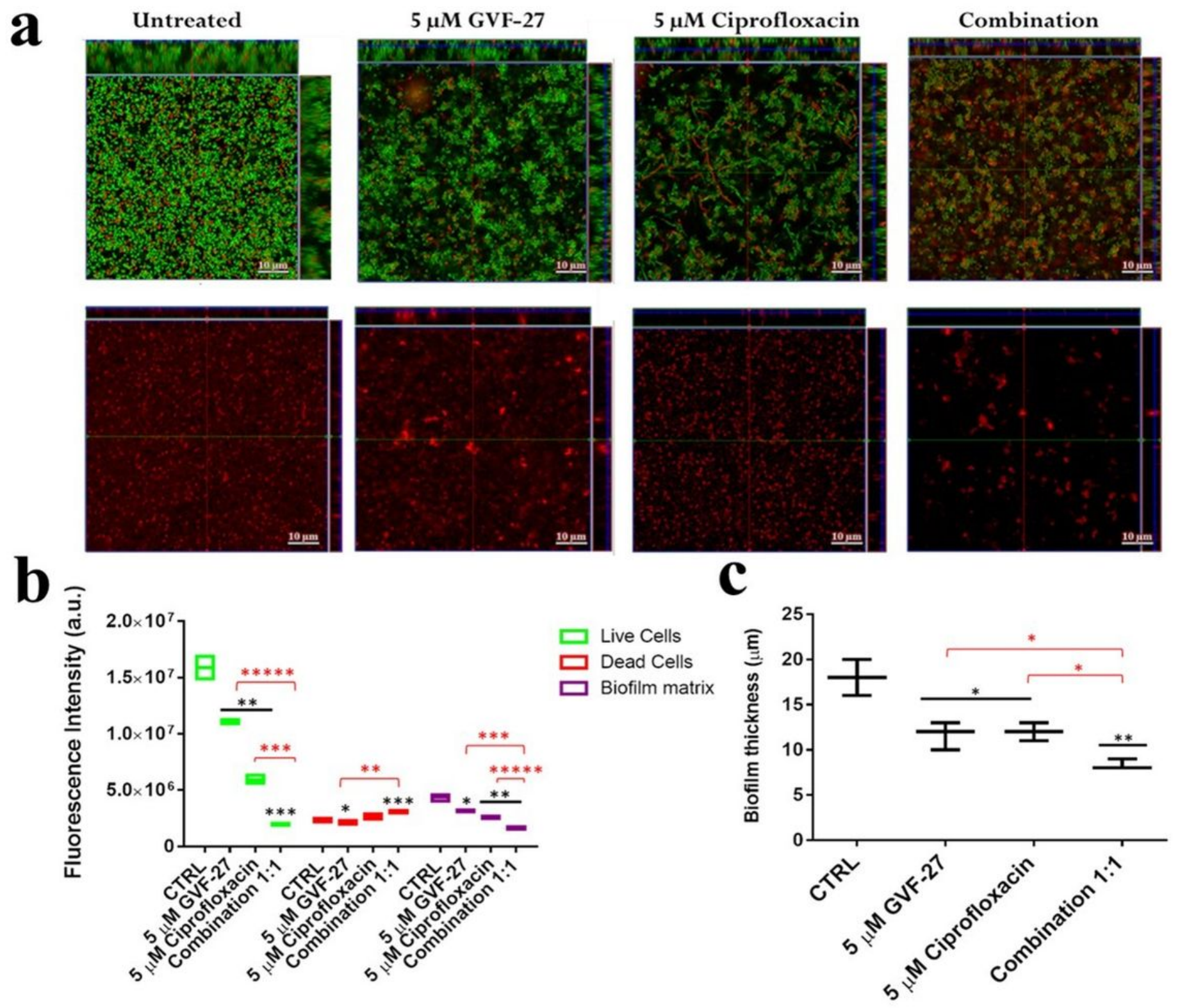

Figure 11

Effects by CLSM of GVF27, ciprofloxacin and a combination of the two compounds on preformed biofilm. Panel a. Biofilm cells were stained by using LIVE/DEAD BacLight bacterial viability kit (Molecular Probes, Eugene, OR) containing 1:1 ratio of Syto-9 (green fluorescence, live cells) and propidium iodide (PI, red fluorescence, dead cells). Images are 3D projections of biofilm structure obtained by laser scanning confocal z-stack using Zen Lite 2.3 software. All images were taken under identical conditions. Significant differences were indicated as $* P<0.05$, $* * P<0.01$ and $* \star * P<0.001$ for treated versus control samples (b); significant differences were indicated as * $P<0.05$, ** $P<0.01$, *** $P<0.001$ and $\star \star \star \star P<0.0001$ for the sample treated with the single agents versus sample treated with the combination of both agents (b and $c)$. 


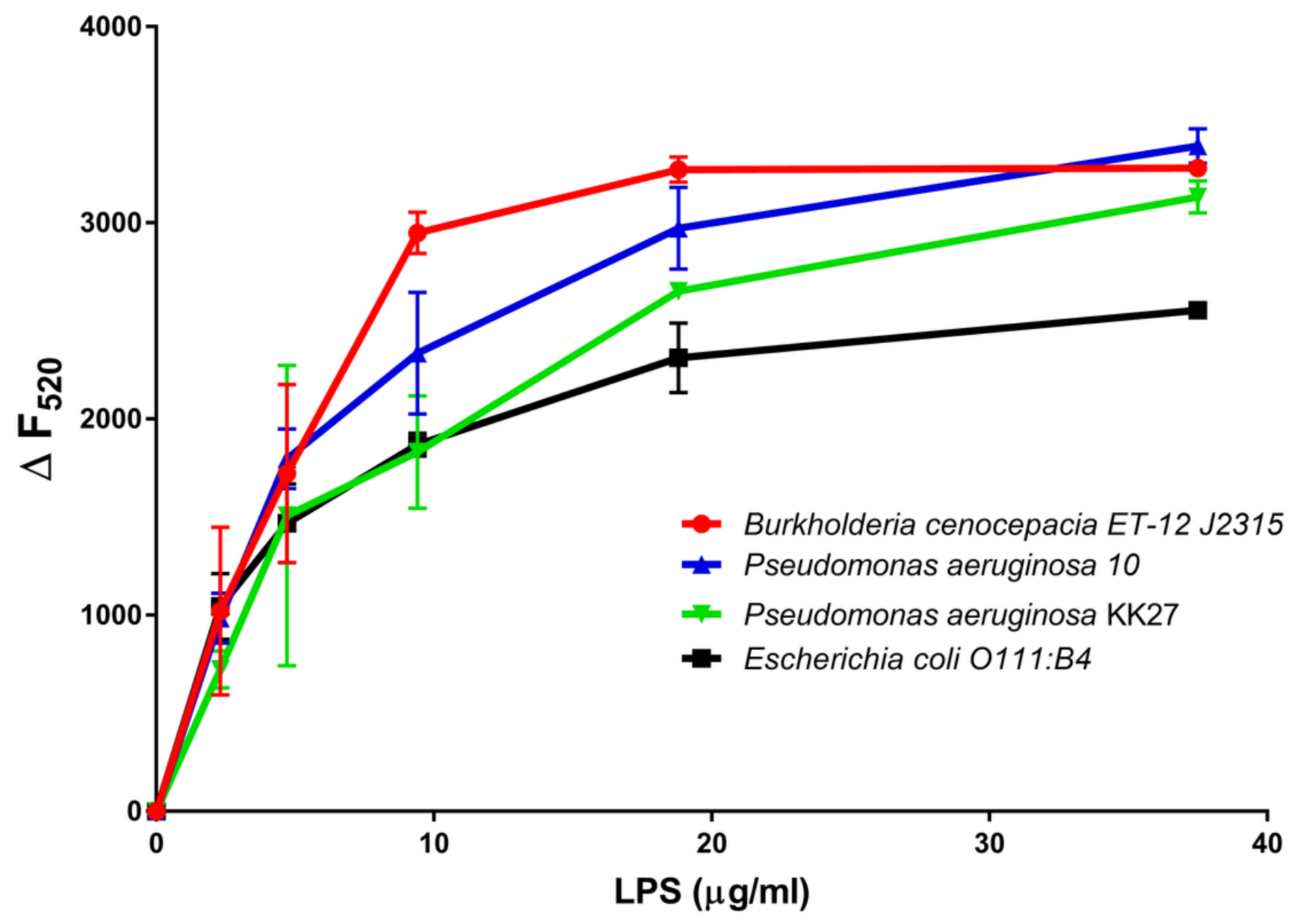

Figure 12

Association determined by analysing fluorescence intensity of FAM-GVF27 in the presence of LPSs isolated from four different bacterial strains. Experiments were performed in $5 \mathrm{mM}$ ammonium acetate buffer (pH 5.0). 1.25 $\mu$ M FAM-GVF27 was individually titrated with increasing concentrations of LPSs. The fluorescence was monitored at an excitation of $485 \mathrm{~nm}$ and at an emission of $520 \mathrm{~nm}$. $\Delta \mathrm{F} 520$ was calculated as follow: $(\Delta F 520)=($ F520 FAM-GVF27buffer - F520 FAM-GVF27LPS) where F520 FAMGVF27buffer is the fluorescence intensity of FAM-GVF27 measured in buffer and F520 FAM-GVF27LPS is the fluorescence intensity of FAM-GVF27 measured in the presence of increasing concentrations of four different LPSs. 
a

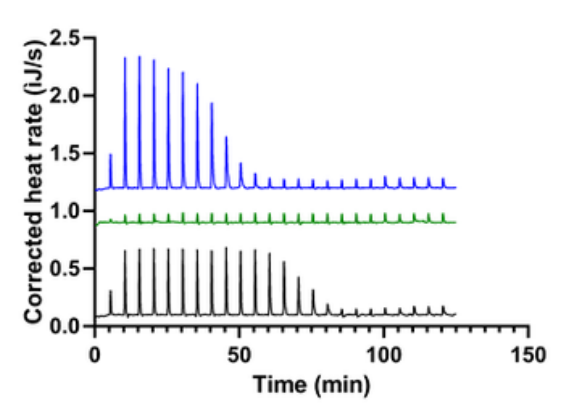

d

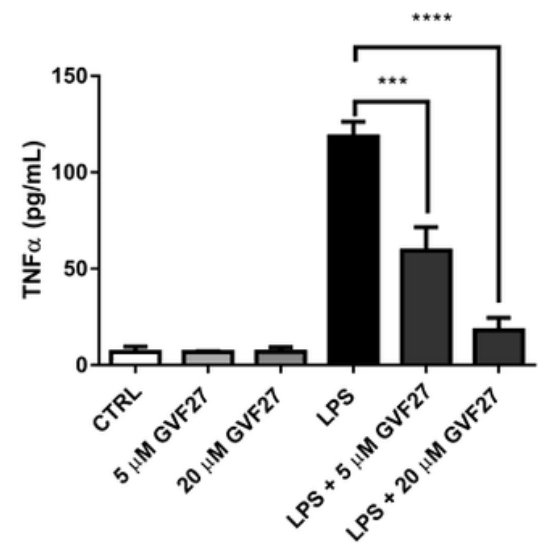

b

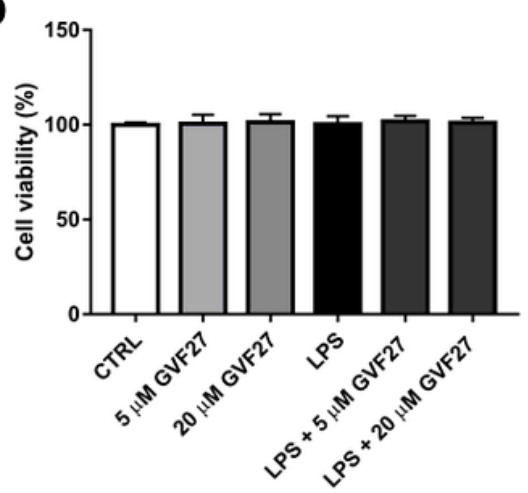

e

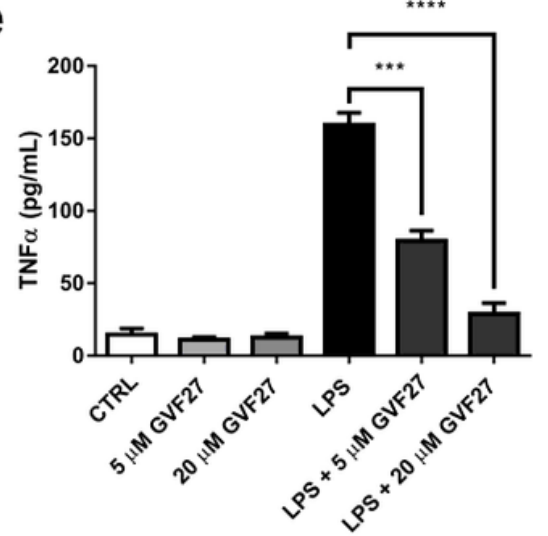

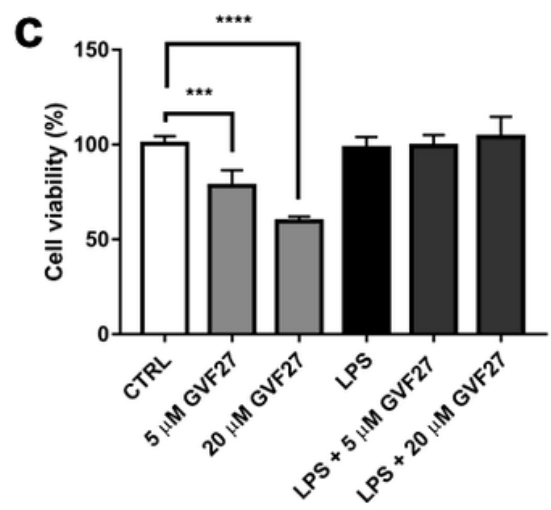

f

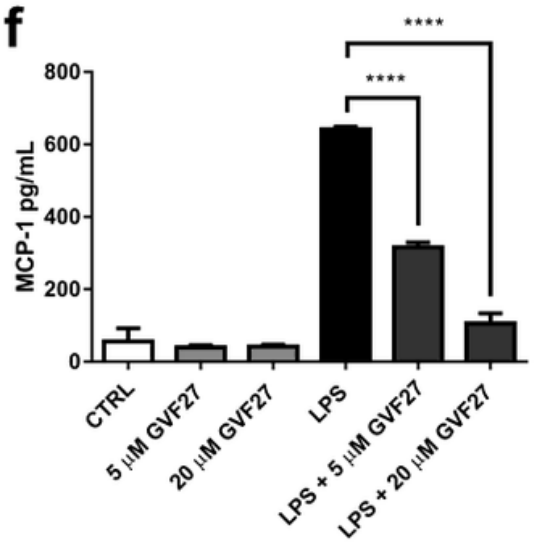

Figure 13

Analyses of GVF27 affinity for LPS ET-12 J2315. Panel a. Representative thermograms of ITC experiments obtained by titration of $200 \mu \mathrm{M}$ GVF27 into $12.5 \mu \mathrm{M}$ LPS from B. cenocepacia ET-12 J2315 (grey), E. coli 0111:B4 (blue) or in control HEPES buffer (green). Panel b. Biocompatibility of GVF27 (5 and $20 \mu \mathrm{M}$ ) alone or in the presence of $1 \mu \mathrm{g} / \mathrm{ml}$ LPS ET-12 J2315 on PMA-differentiated THP-1 cells.

Panel c. Biocompatibility of GVF27 $(5$ and $20 \mu \mathrm{M})$ alone or in the presence of $1 \mu \mathrm{g} / \mathrm{ml}$ LPS ET-12 J2315 on undifferentiated THP-1 cells. Panel d. Effect of GVF27 ( 5 and $20 \mu \mathrm{M})$ on the release of TNF- $a$ in untreated or LPS ET-12 J2315 infected undifferentiated THP-1 cells; Panel e. Effect of GVF27 (5 and 20 $\mu \mathrm{M})$ on the release of TNF- $\alpha$ in untreated or LPS ET-12 J2315 infected PMA-differentiated THP-1 cells.

Panel $\mathrm{f}$. Effect of GVF27 ( 5 and $20 \mu \mathrm{M}$ ) on the release of MCP-1 in untreated or LPS ET-12 J2315 infected PMA-differentiated THP-1 cells. Three independent experiments were performed, and, for all the experimental points, ${ }^{*} P<0.05,{ }^{*} P<0.01$, or ${ }^{*} * \mathrm{P}<0.001$ were obtained for control (LPS) versus samples treated with both GVF27 and LPS.

\section{Supplementary Files}

This is a list of supplementary files associated with this preprint. Click to download.

- videoclip1.mp4

- videoclip2.mp4 